Louisiana State University

LSU Digital Commons

LSU Master's Theses

Graduate School

2007

\title{
Film cooling from a row of holes supplemented with anti vortex holes
}

Alok Dhungel

Louisiana State University and Agricultural and Mechanical College

Follow this and additional works at: https://digitalcommons.Isu.edu/gradschool_theses

Part of the Mechanical Engineering Commons

\section{Recommended Citation}

Dhungel, Alok, "Film cooling from a row of holes supplemented with anti vortex holes" (2007). LSU Master's Theses. 421.

https://digitalcommons.Isu.edu/gradschool_theses/421

This Thesis is brought to you for free and open access by the Graduate School at LSU Digital Commons. It has been accepted for inclusion in LSU Master's Theses by an authorized graduate school editor of LSU Digital Commons. For more information, please contact gradetd@lsu.edu. 


\title{
FILM COOLING FROM A ROW OF HOLES SUPPLEMENTED WITH ANTI VORTEX HOLES
}

\author{
A Thesis \\ Submitted to the Graduate Faculty of the \\ Louisiana State University and \\ Agricultural and Mechanical College \\ In partial fulfillment of the \\ requirements for the degree of \\ Master of Science in Mechanical Engineering
}

The Department of Mechanical Engineering

by

Alok Dhungel

B.E., Regional Engineering College-Rourkela, 2002

August 2007 


\section{ACKNOWLEDGEMENT}

First of all I would like to express my sincere gratitude to Dr. Srinath V. Ekkad for providing me with an opportunity to work in this research. Without his guidance, financial support and help, this work would never have been completed. I'd like to thank him for his belief and faith in me.

I would also like to thank my committee members Dr. Shengmin Guo and Dr. Dorel Moldovan for their valuable suggestions. I am indebted to my lab mates Yiping Lu, Yap-Sheng Goh, Eric Esposito and Wynn Phillips for their help. I'm grateful to Mr. Jim Layton, Jr. and Mr. Barry Savoy from the machine shop for helping me with the machine work.

Last, but not the least, I would like to thank my friends and family for their motivation, support and help. 


\section{TABLE OF CONTENTS}

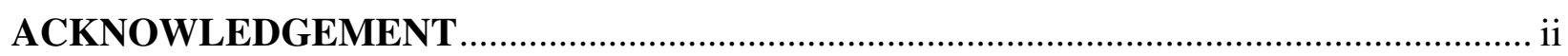

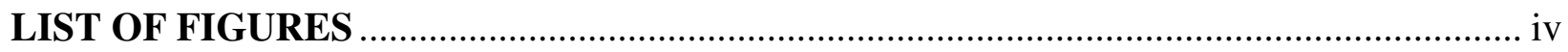

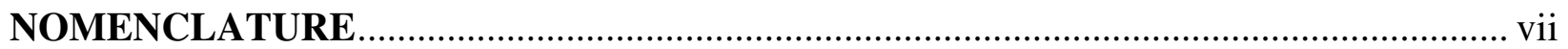

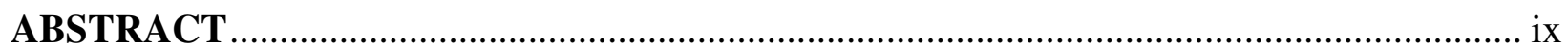

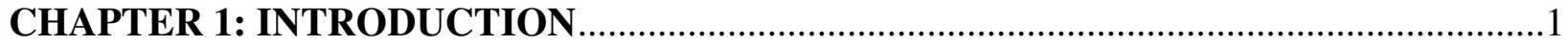

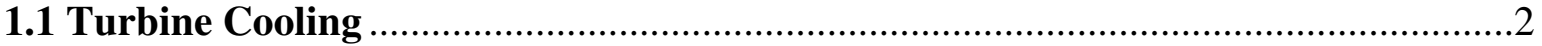

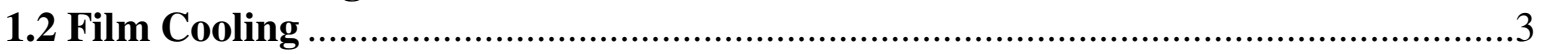

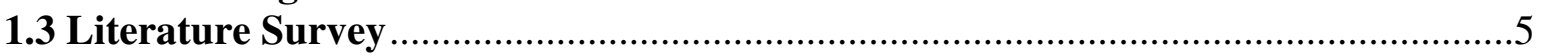

1.4 Experimental Objectives ……………………………………………………....

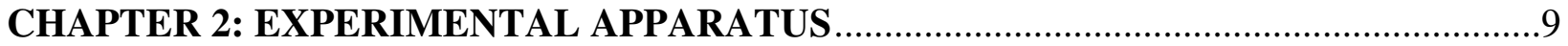

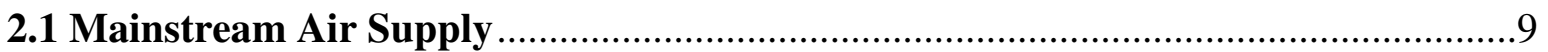

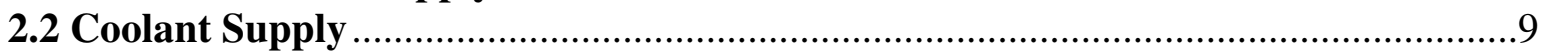

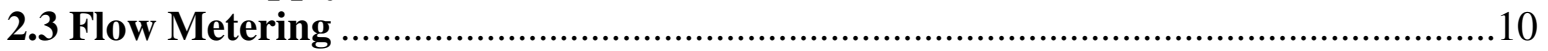

2.4 Temperature Measurements ...........................................................................11

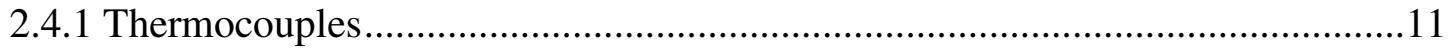

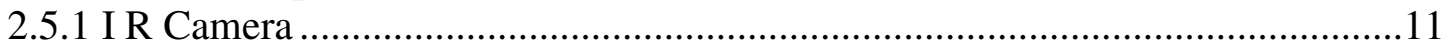

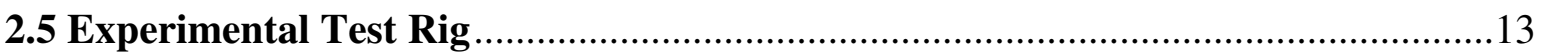

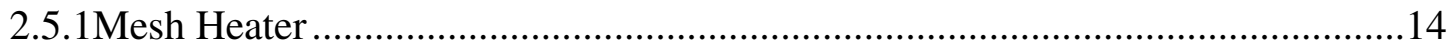

2.6 Film Cooling Hole Geometry …………………............................................15

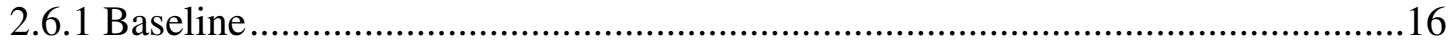

2.6.2 Shaped Diffuser Holes ....................................................................................

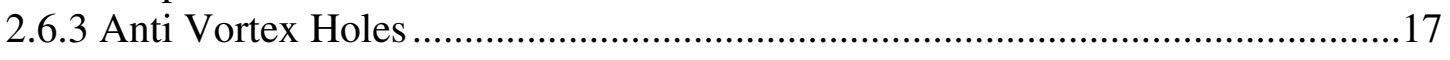

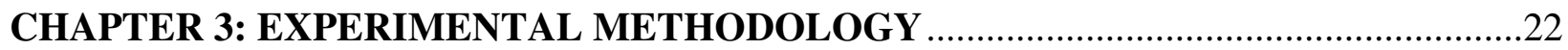

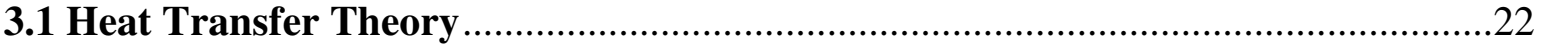

3.1.1 Heat Transfer Coefficient Measurement............................................................22

3.1.2 Film Cooling Effectiveness Measurement...................................................24

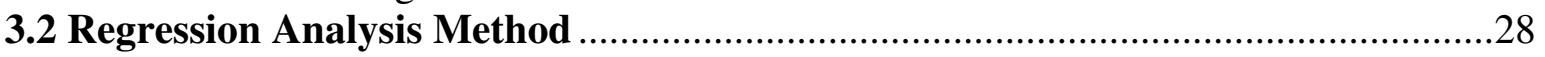

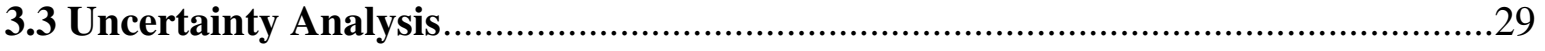

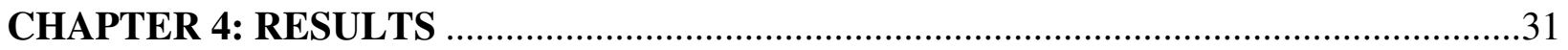

4.1 Film Cooling Effectiveness .................................................................................

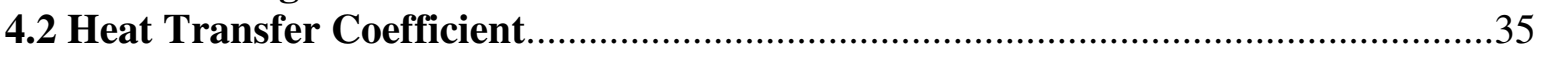

4.3 Spanwise Averaged Film Cooling Effectiveness......................................................38

4.4 Spanwise Averaged Heat Transfer Coefficient Ratio ................................................41

4.5 Overall Area Averaged Film Cooling Effectiveness ……………………………....4

4.6 Overall Area Averaged Heat Transfer Coefficient Ratio ..........................................4

4.7 Overall Area Averaged Heat Flux Ratio …………..............................................45

4.8 Discussions .............................................................................................................

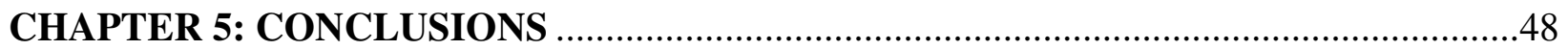

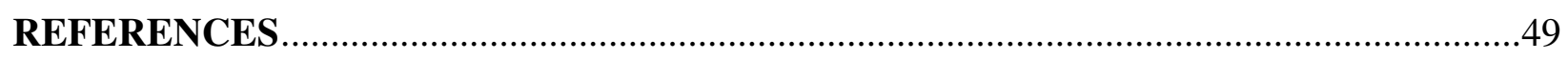

VITA 


\section{LIST OF FIGURES}

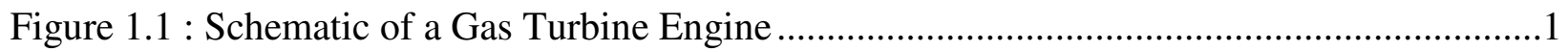

Figure 1.2 : Specific Core Power Productions as a Function of Rotor Inlet Tempetarure ...............2

Figure 1.3 : Cooling Concept of a Modern Multi-Pass Turbine Blade...........................................

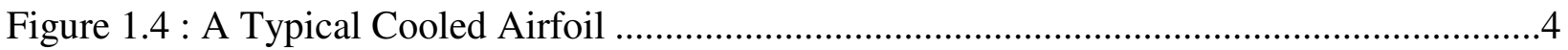

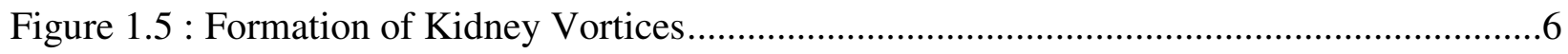

Figure 2.1 : AC TECH Variable Speed AC Motor High Capacity Fan...........................................

Figure 2.2 : Atlas Copco GR 110 Two-Stage Screw Compressor...................................................10

Figure 2.3 : Rotameter with a Maximum Capacity of 60 SCFM................................................11

Figure 2.4 : FLIR ThermaCAM SC 500 Infra Red Camera ..........................................................12

Figure 2.5 : Overview of the Experimental Setup ................................................................13

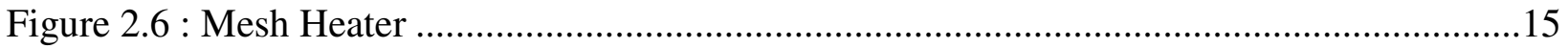

Figure 2.7 : Thermal Response of Mesh Heater ......................................................................15

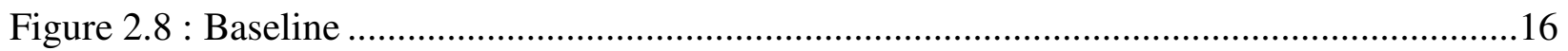

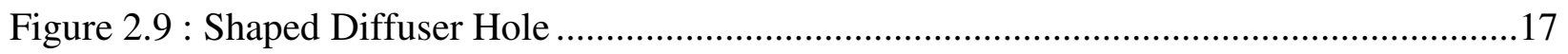

Figure 2.10 : Top and Side Section View of Shaped Diffuser Hole ................................................17

Figure 2.11 : Test Plate with Anti Vortex Holes ........................................................................18

Figure 2.12: Top View (a), Front View (b) and Side View (c) of the Anti Vortex Hole

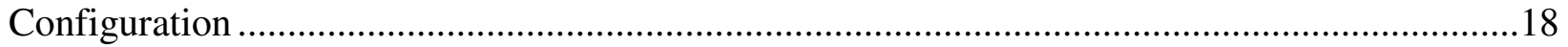

Figure 2.13 : Anti Vortex Hole Orientation- Case 1.....................................................................19

Figure 2.14 : Anti Vortex Hole Orientation- Case 2 2.................................................................19

Figure 2.15 : Anti Vortex Hole Orientation- Case 3 ………………………………...................20

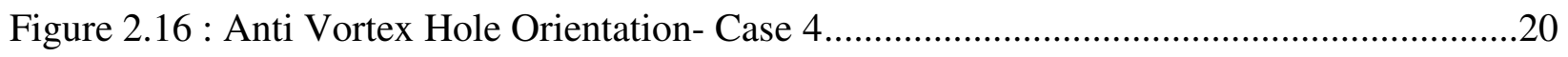

Figure 2.17 : Anti Vortex Hole Orientation- Case 5 ..................................................................20 
Figure 2.18 : Anti Vortex Hole Orientation- Case 6.

Figure 3.1 : Flow over a Semi Infinite Slab. .22

Figure 3.2 : Schematic of Film Coling Concept .25

Figure 3.3 : Curve Fit of Raw Data from a Single Pixel. .28

Figure 4.1a : Detailed Film Cooling Effectiveness distribution for Baseline and Case 1 at Different Blowing Ratios .31

Figure 4.1b : Detailed Film Cooling Effectiveness distribution for Case 2 and Case 3 at Different Blowing Ratios.

Figure 4.1c : Detailed Film Cooling Effectiveness distribution for Case 4 and Case 5 at Different Blowing Ratios. .34

Figure 4.1d : Detailed Film Cooling Effectiveness distribution for Case 6 and Shaped Hole at Different Blowing Ratios .35

Figure 4.2a : Detailed Heat Transfer Coefficient $\left(\mathrm{W} / \mathrm{m}^{2} \mathrm{~K}\right)$ Distribution for Baseline, Cases 1 and 2 at Different Blowing Ratios . 36

Figure 4.2b : Detailed Heat Transfer Coefficient $\left(\mathrm{W} / \mathrm{m}^{2} \mathrm{~K}\right)$ Distribution for Cases 3,4 and 5 at Different Blowing Ratios .37

Figure 4.2c : Detailed Heat Transfer Coefficient $\left(\mathrm{W} / \mathrm{m}^{2} \mathrm{~K}\right)$ Distribution for Case 6 and Shaped Holes at Different Blowing Ratios .38

Figure 4.3a : Effect of Anti Vortex Hole Geometry on Spanwise Averaged Film Cooling Effectiveness Distribution at Blowing Ratio 0.5 .....

Figure 4.3b : Effect of Anti Vortex Hole Geometry on Spanwise Averaged Film Cooling Effectiveness at Blowing Ratio 1.0. 39

Figure 4.3c : Effect of Anti Vortex Hole Geometry on Spanwise Averaged Film Cooling Effectiveness at Blowing Ratio 1.5 and 2.0...... 40

Figure 4.4a : Effect of Anti Vortex Hole Geometry on Spanwise Averaged Heat Transfer Coefficient Ratio at Blowing Ratio 0.5 41

Figure 4.4b : Effect of Anti Vortex Hole Geometry on Spanwise Averaged Heat Transfer Coefficient Ratio at blowing ratio 1.0 ...... .42

Figure 4.4c : Effect of Anti Vortex Hole Geometry on Spanwise Averaged Heat Transfer Coefficient Ratio at blowing ratio 1.5 . .43 
Figure 4.4d : Effect of Anti Vortex Hole Geometry on Spanwise Averaged Heat Transfer

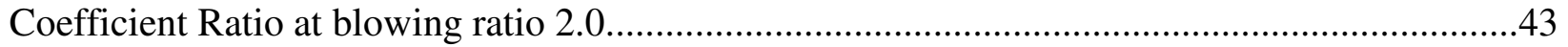

Figure 4.5 : Effect of Blowing Ratio on Overall Area-Averaged Film Effectiveness.................44

Figure 4.6 : Effect of Blowing Ratio on Overall Area-Averaged Heat Transfer Coeff. Ratio ......45

Figure 4.7 : Effect of Blowing Ratio on Overall Heat Flux Ratio............................................45

Figure 4.8 : (a) Stagnation Temperature $\left(\mathrm{T} / \mathrm{T}_{\text {in }}\right)$ and (b) Secondary Flow Vectors Colored by

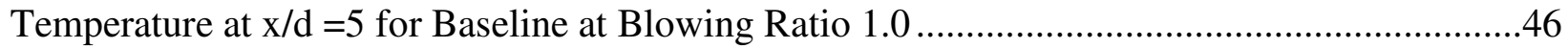

Figure 4.9 : (a) Stagnation Temperature $\left(\mathrm{T} / \mathrm{T}_{\mathrm{in}}\right)$ and (b) Secondary Flow Vectors Colored by Temperature at $\mathrm{x} / \mathrm{d}=5$ for Anti Vortex Case 6 at Blowing Ratio 1.0 ......................................47 


\section{NOMENCLATURE}

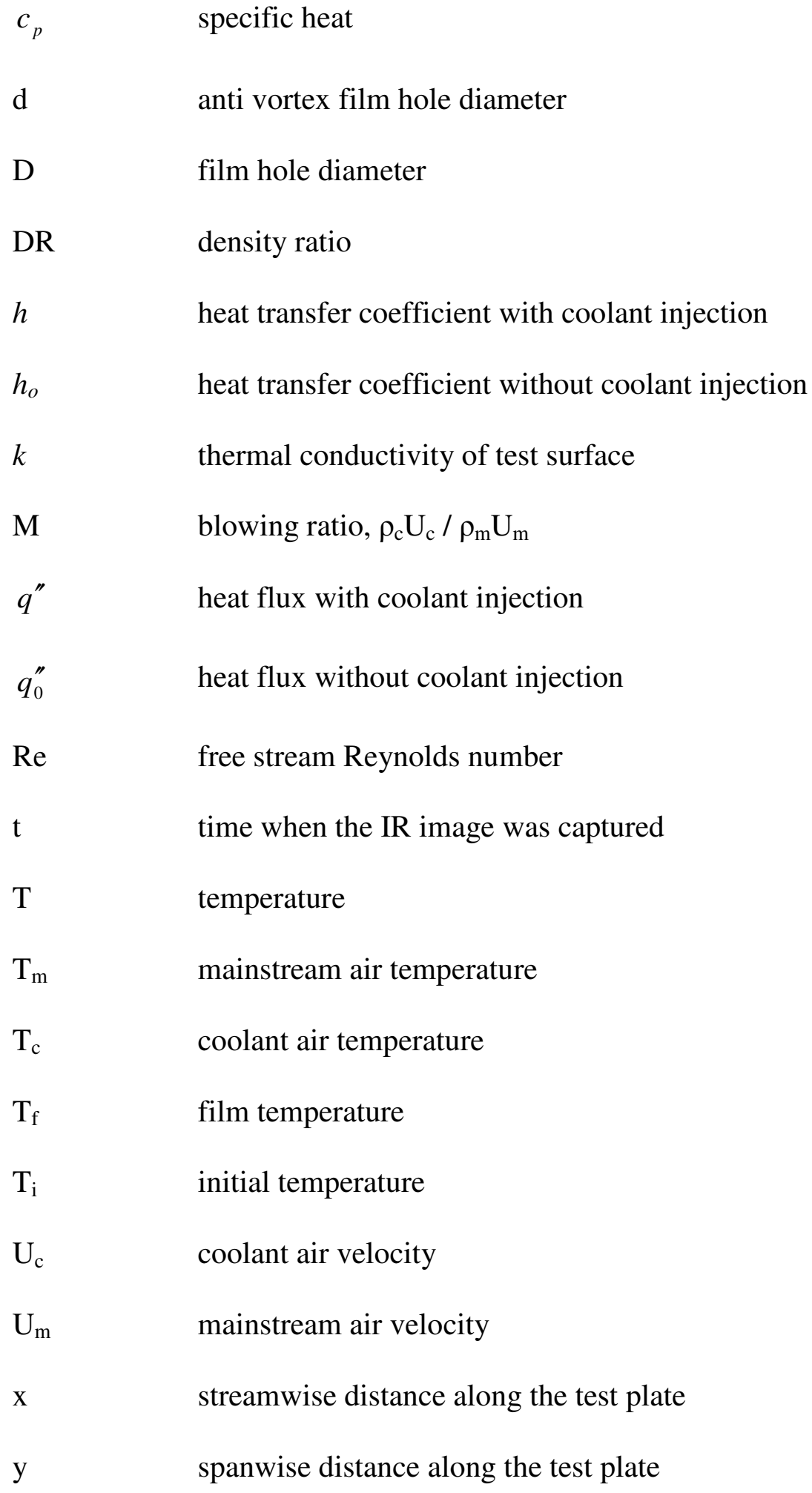




\section{Greek Symbols}

$\eta \quad$ film cooling effectiveness

$\phi \quad$ overall cooling effectiveness

$\alpha$

thermal diffusivity 


\begin{abstract}
Film cooling is a technique employed to protect the external surface of gas turbine blades from the hot mainstream gas by ejecting the internal coolant air through discrete holes or slots at several locations on the blade exterior surface. Passing the coolant through conventional cylindrical holes causes a pair of vortices to form which lifts off the coolant jet instead of letting it adhere to the surface. The present study aims at investigating the enhanced cooling performance caused by addition of anti-vortex holes to the main cylindrical film cooling holes. Both heat transfer coefficient and film cooling effectiveness are determined experimentally downstream of the exit of the film cooling holes on a flat plate by a single test using the transient Infra Red thermography technique. A total of six different cases with variations in geometry and orientation of the anti vortex holes in relation to the main film cooling holes are thoroughly investigated.

Results suggested that the presence of anti vortex holes mitigates the effect of the pair of anti vortices. When the anti vortex holes are nearer to the primary film cooling holes and are developing from the base of the primary holes, better film cooling is accomplished as compared to other anti vortex holes orientation. When the anti vortex holes are laid back in the upstream region, film cooling diminishes considerably. Although an enhancement in heat transfer coefficient is seen in cases with high film cooling effectiveness, the overall heat flux ratio as compared to standard cylindrical holes is much lower. Thus cases with anti vortex holes placed near the main holes certainly show promising results.
\end{abstract}




\section{CHAPTER 1: INTRODUCTION}

The history of human controlled power flight dates back to December of 1903, when the Wright brothers successfully built and tested their aircraft. Since then scientists have been perpetually trying to improve the aircraft in all facets. Flight performance in terms of greater flight speed, altitude, range and maneuverability; cost in terms of better fuel economy, lower cost of production and maintenance, increased lifetime; better controls and navigations are few of the areas where a constant research is going on. Today turbine engines have been able to carry aircrafts past the speed of sound and are one of the most cheapest and reliable sources of travel. Gas turbine engines are also used to power ships, trains and electric generators.

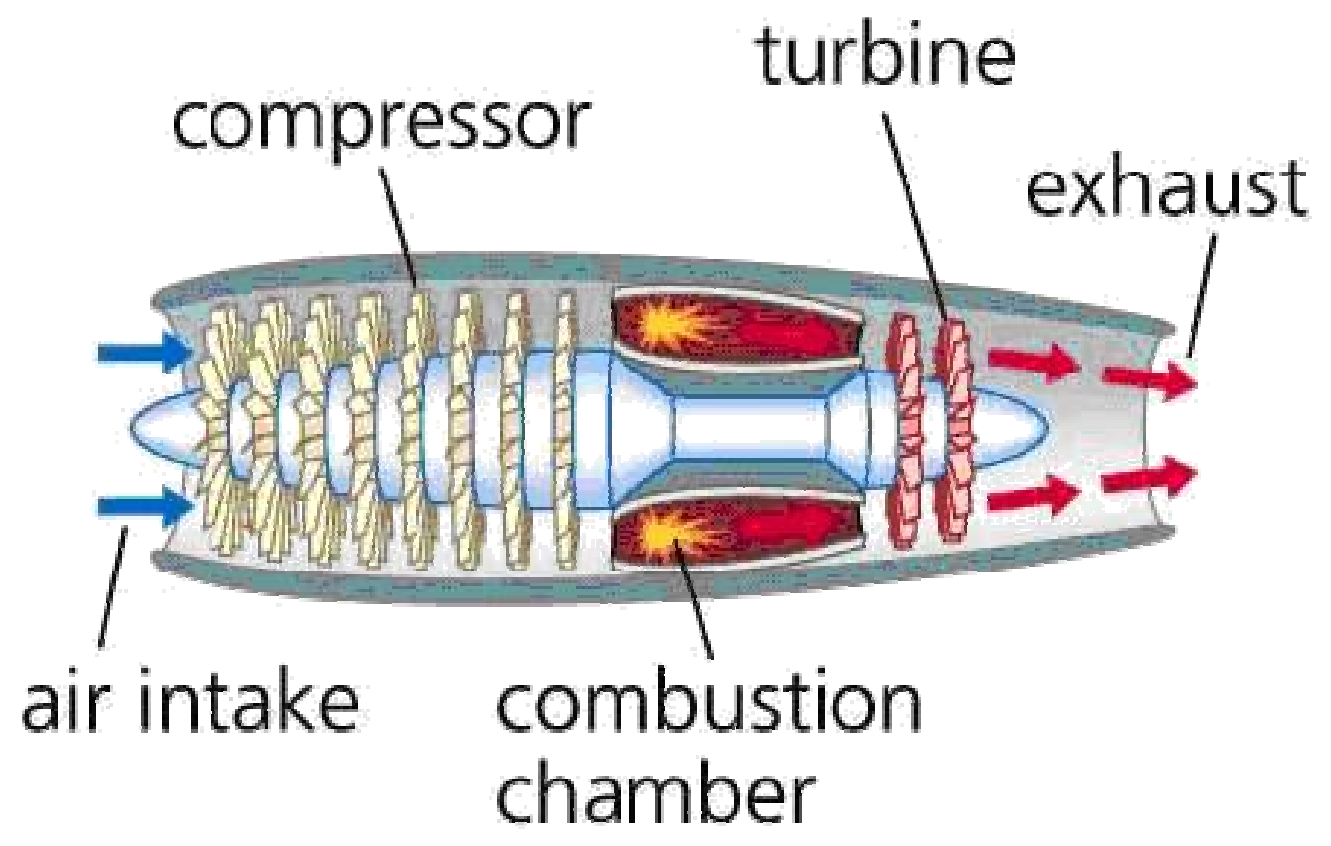

Figure 1.1: Schematic of Gas Turbine Engine [1]

Fig 1.1 shows a basic layout of a gas turbine engine. The intake air is compressed by a compressor. The compressed air is burnt by spraying fuel at the combustor. The turbine draws energy from the hot and high pressured air coming from the combustor. The hot air is then released through the nozzle providing thrust. 


\subsection{Turbine Cooling}

The demand of engines with a higher thrust to weight ratio to satisfy the needs of today has posed a challenge to engineers to come up with ways to improve the efficiency and thrust of engines. Thermal efficiency and power output of gas turbine increases with turbine rotor inlet temperature. This is shown dramatically in figure 1.2.

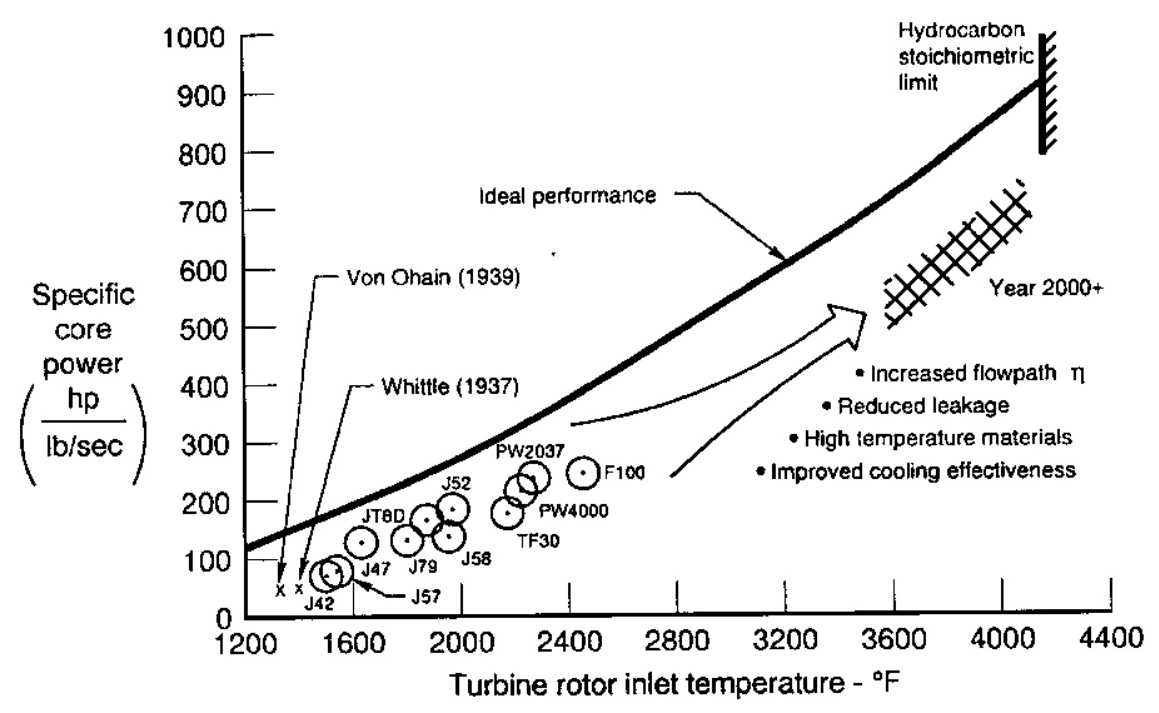

Figure 1.2: Specific Core Power Productions as a Function of Rotor Inlet Temperature [2]

The operating temperature of the modern day gas turbines are far greater than the permissible temperature of the blade material. Thus cooling of the blades is indispensible. The blades are cooled by extracting air from the compressor of the engine. Since this causes a decrease in the thermal efficiency, cooling technique has to be properly designed and optimized. Gas turbine blades are cooled both internally and externally.

Figure 1.3 shows a conceptual concept of a modern turbine blade cooling. In internal cooling, the bypass air from the compressor is fed inside the blade, which is hollow. This cold air, in the trailing air region, cools the blade by extracting heat from the pin fins. The air then passes through the serpentine passages with rib turbulators on the inner side of the blade in the mid chord region extracting hear from the inside surface of the blade. In the leading edge region, 
the air passes through a plate with small holes, i.e. the impingement insertion, and impinges on the inside wall of the leading edge and thus cooling the internal surface of the blade.

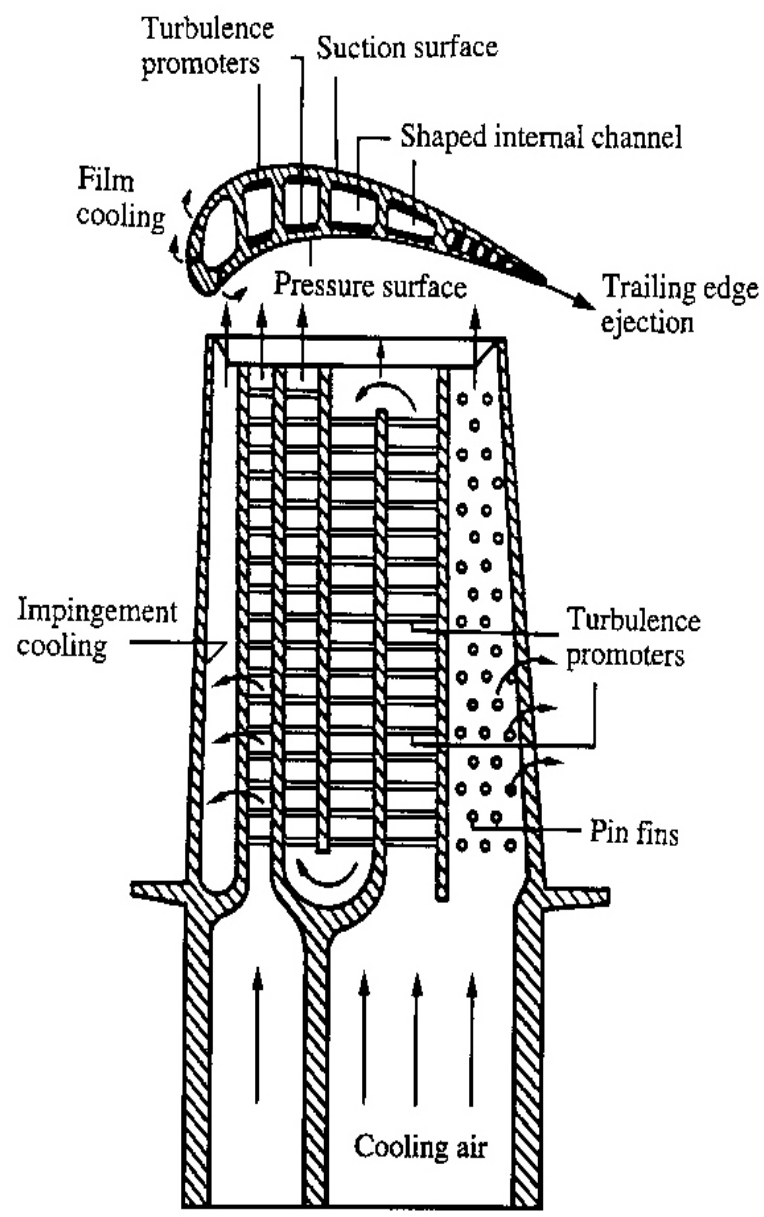

Figure 1.3: Cooling Concept of a Modern Multi-Pass Turbine Blade [3]

The air used in internal cooling is ejected out of the blade from the discrete holes drilled at various positions in the blade surface. The air thus ejected forms a protective film that protects the blade surface from the hot detrimental mainstream air. This method of externally cooling the blade is known as film cooling.

\subsection{Film Cooling}

Film Cooling is the introduction of a secondary fluid (coolant or injected fluid) at one or more discrete locations along a surface exposed to a high temperature environment to protect that 
surface not only in the immediate region of injection but also in the downstream region. [4]. Film cooling protects the surface directly by forming a protective layer of cold air as compared to internal cooling, where blade is cooled by extracting heat by convection. Film Cooling also provides cooling from internal convection in the film holes. Turbine airfoil surfaces, shrouds, blade tips, and end walls are all cooled by film cooling. Figure 1.4 shows a typical cooled airfoil.

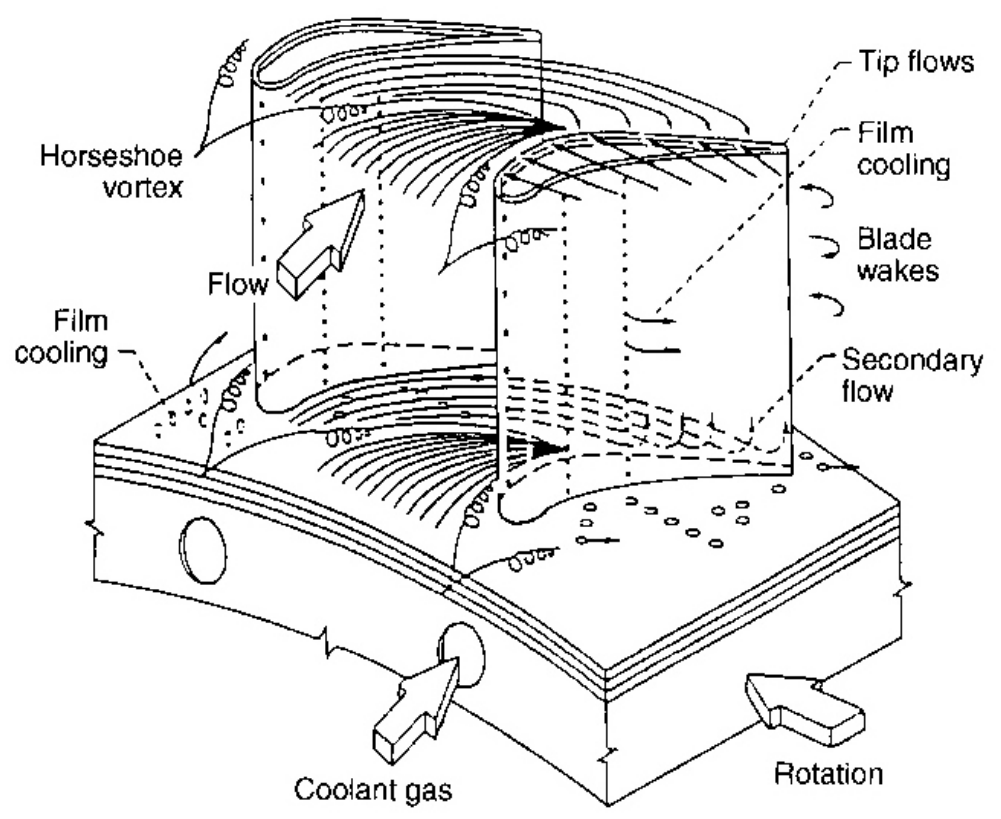

Figure 1.4: A Typical Cooled Airfoil [5]

It also shows location of discrete holes for film cooling from where the cold coolant forms a protective blanket which protects the airfoil surface from the hot mainstream air. This protection brings about a reduction in thermal load to the airfoil. Designers need to know the net heat load into the component surface when film is injected. Due to the complex nature of discrete hole injection, there is a need to know the local wall temperature under the film and the gas side heat transfer coefficient with film injection. Both these components are required to estimate the reduced heat load to the surface. 
Film cooling research on flat surface is common. Flat surface models can be used to study the effects of individual parameters with relative ease and are less expensive. Studies have proved that the results obtained on simple flat surface models can be applied to real engine designs with slight corrections [6]. The effects of geometrical parameters like hole geometry, shape, size and spacing of the holes and flow parameters like coolant to mainstream mass flux, temperature ratio, mainstream Reynolds number, velocity, etc. have been studied on flat surfaces.

\subsection{Literature Survey}

Research on flat plate film cooling has been done since a long time. Goldstein [4] has summarized the early researches on film cooling. The early research concentrated mainly on the film cooling from slots of different geometry and orientations. Both analytical and experimental results are listed. In a gas turbine engine, film cooling from a slot is not practical because of limitations in mechanical strength and thus, also considering the manufacturability, cooling from discrete holes must be employed. Goldstein [4] studied the adiabatic film cooling effectiveness of a circular tubes (ending flush to the surface) inclined at 35 degrees to the main flow. Unlike two dimensional (2-D) flow in a slot, this 3-D flow doesn't provide uniform cooling in the span wise direction. Another disadvantage of the introducing coolant through cylindrical holes is that when the coolant to mainstream momentum flux ratio is higher ( $\sim$ or above) then the jet lifts off from the surface and the effectiveness is lower than the slot film cooling using the same amount of coolant air.

Andreopoulous and Rodi [7] studied the behavior of a single jet and mainstream interaction. There is a mutual deflection of the jet and the mainstream. The jet is pushed towards the bottom wall and the mainstream is deflected as if the jet forms a solid boundary. At a low momentum ratio of 0.25 , the mainstream pushes the jet to adhere to the bottom wall .At a higher 
momentum ratio of 4.0 , the jet penetrates into the mainstream before it is bent. There is a complicated three- dimensional separation region downstream of the jet in both cases, which is more pronounced at the higher momentum ratio.

There have been vast studies in the field of interaction between coolant jet from inclined cylindrical holes and the mainstream flow. The interaction results in the formation of kidney vortices, i.e. a pair of counter rotating vortices [8]. Figure 1.5 shows the formation of the counter rotating vortices.

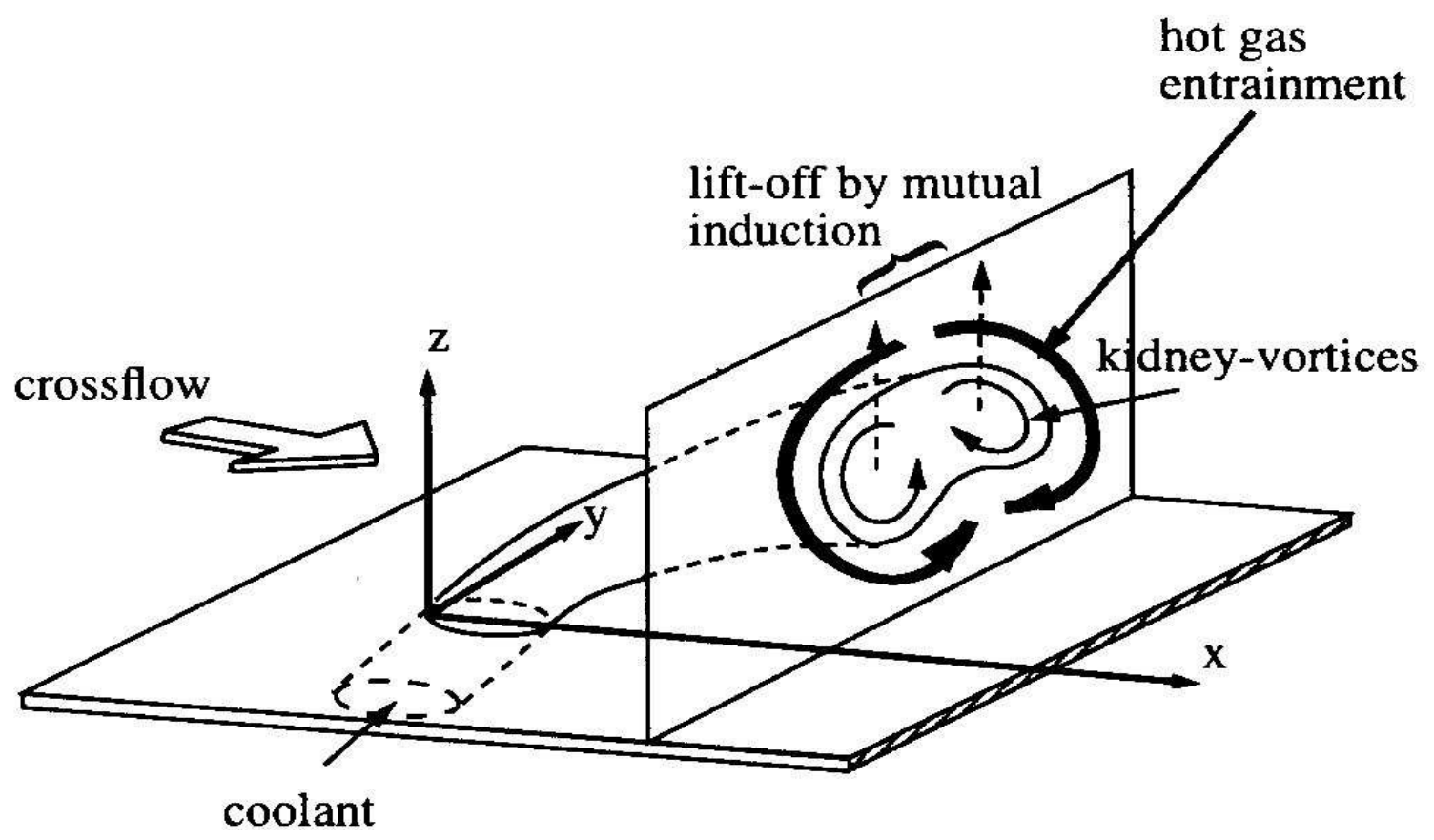

Figure 1.5: Formation of Kidney Vortices [8]

These vortices are detrimental to film cooling because it brings about two undesirable effects. Firstly, the hot mainstream air is forced to enter beneath the jet, thus heating the turbine blade wall. Secondly, the mutual interaction between the vortex pair tends to lift the jet off the turbine blade surface which diminishes the film cooling.

Lemmon et al. [9] showed that the formation of these counter rotating vortices is dictated by the shear layer between the mainstream flow and the coolant jet and not due to the viscous 
wall effect in the film cooling hole or plenum. Haven et al [10] showed that the when the exit of the film cooling holes are expanded laterally, the distance between the two vortices is increased thus delaying the jet lift off. A properly shaped hole also generates a pair of anti-kidney vortices which are opposite to the kidney vortices in the sense of rotation. These two pair cancels each other and jet lift off is prevented.

Several studies have investigated compound hole injection. Ligrani et al. [11-12] studied the effects of compound angle injection for a single row and two staggered rows of holes. They pointed out that compound angle injection significantly improved film cooling as compared to simple angled hole keeping all other parameters constant. Compound angled injection is higher due to stronger lateral momentum and more spreading of jets, providing higher effectiveness over a large span wise region. Sen et al. [13] and Schmidt et al. [14] compared simple angle injection to compound angle injection and shaped hole injection. Although they provided heat transfer coefficient and film effectiveness results, the former data was very sparse. Ekkad et al. [15-16] provided detailed surface heat transfer measurements using the transient liquid crystal technique. Likewise, there have been a number of studies on film cooling by shaped holes. Makki and Jakubowski [17] used forward- expanded holes and studied its effect. Sen et al. [13] and Schmidt et al. [14] compared simple angled holes and compound angled holes to shaped holes and found out that the shape hole with forward expansion provided significantly larger lateral film coverage than both the other cases. Gritsch et al. [18-19] presented both discharge coefficients and film cooling effectiveness for three hole geometries. They compared simple angle cylindrical holes, fan shaped holes and laidback fan shaped holes. From their results, they indicated that laidback fan shaped holes provide higher laterally averaged film cooling effectiveness due to increased lateral spreading of jets. Dittmar et al. [20] presented an assessment of various film hole configurations in a simulated turbine surface experiment. They 
indicated that shaped holes with compound angle produce the best effective cooling compared to the other geometries.

Sargison et al. [21] studied a converging slot-hole geometry in which the hole transitions from circular to slot with convergence in the axial direction and divergence laterally. The attempt was to make the three-dimensional nature of the jet into a two-dimensional slot film. The results were aimed at improving effectiveness. Lu et al. [22] introduced a crescent shaped exit geometry and compared it with the baseline cylindrical hole exit and the converging slot-hole geometry. They showed that the crescent exit performed well at all blowing ratios producing almost an effectiveness of 0.7-0.9 within 3-5 hole diameters downstream and high effectiveness values of 0.4 at X/D 15. The converging hole-slot geometry was also effective and similar to the crescent shape geometry. Most of the above studies with shaped hole focused on reducing the upward momentum of the jets by increasing the hole exit area or transforming the hole to slots. The present study focuses on producing similar results using the anti-vortex air as supplemental holes without altering the hole exit area.

\subsection{Experimental Objectives}

The objective of this study is to design and test innovative film cooling cylindrical holes supplemented with a pair of cylindrical anti vortex holes branching out from the main cylindrical holes. It is hoped that the coolant flow from the anti-vortex film cooling holes would be able to mitigate the effect of kidney vortices that causes the jet to lift off. The coolant that is released from the main cylindrical film cooling holes is also reduced in quantity, thus it is hoped that the jet adheres to the base plate shielding the hot mainstream gas from the base plate. 


\section{CHAPTER 2: EXPERIMENTAL APPARATUS}

A test rig was built to study the heat transfer coefficient and film cooling effectiveness from a single transient test. All the apparatus used for the study are explained in detail. The geometry and orientation of the six different anti vortex film cooling holes are also explained.

\subsection{Mainstream Air Supply}

The mainstream air supply is the ambient air drawn by a high capacity variable speed AC motor blower fitted with an AC TECH variable speed AC motor drive. A dial pad control panel provided on the $\mathrm{AC}$ motor drive allows for a precise adjustment of fan speed of the blower. The blower outlet is connected to the nozzle of the test rig by a custom made GI sheet duct. Figure 2.1 shows the blower securely bolstered to a high lifted rack.

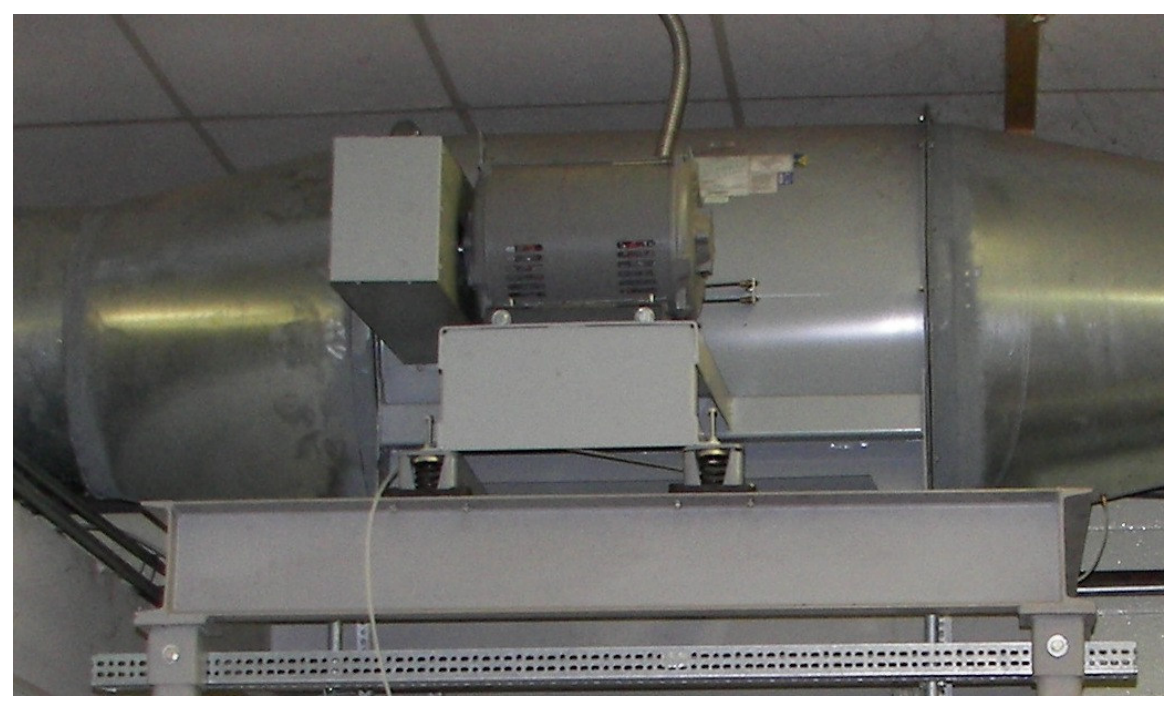

Figure 2.1: AC TECH Variable Speed AC Motor High Capacity Fan

\subsection{Coolant Supply}

The present study employs an Atlas Copco GR 110 two-stage screw compressor in conjunction with a Pneumatech Inc. heatless regenerative air dryer as the source of coolant air supply. The compressed air leaving the compressor is fed to a dryer to remove the moisture

content in it. The compressed dry air is then stored in a $7.57 \mathrm{~m}^{3}$ pressure vessel. Drawing the 
compressed air from the storage tank rather than directly from the compressor minimizes the line pressure fluctuations caused by the periodic cycling of the compressor. Figure 2.2 is a picture of the Atlas Copco GR 110.

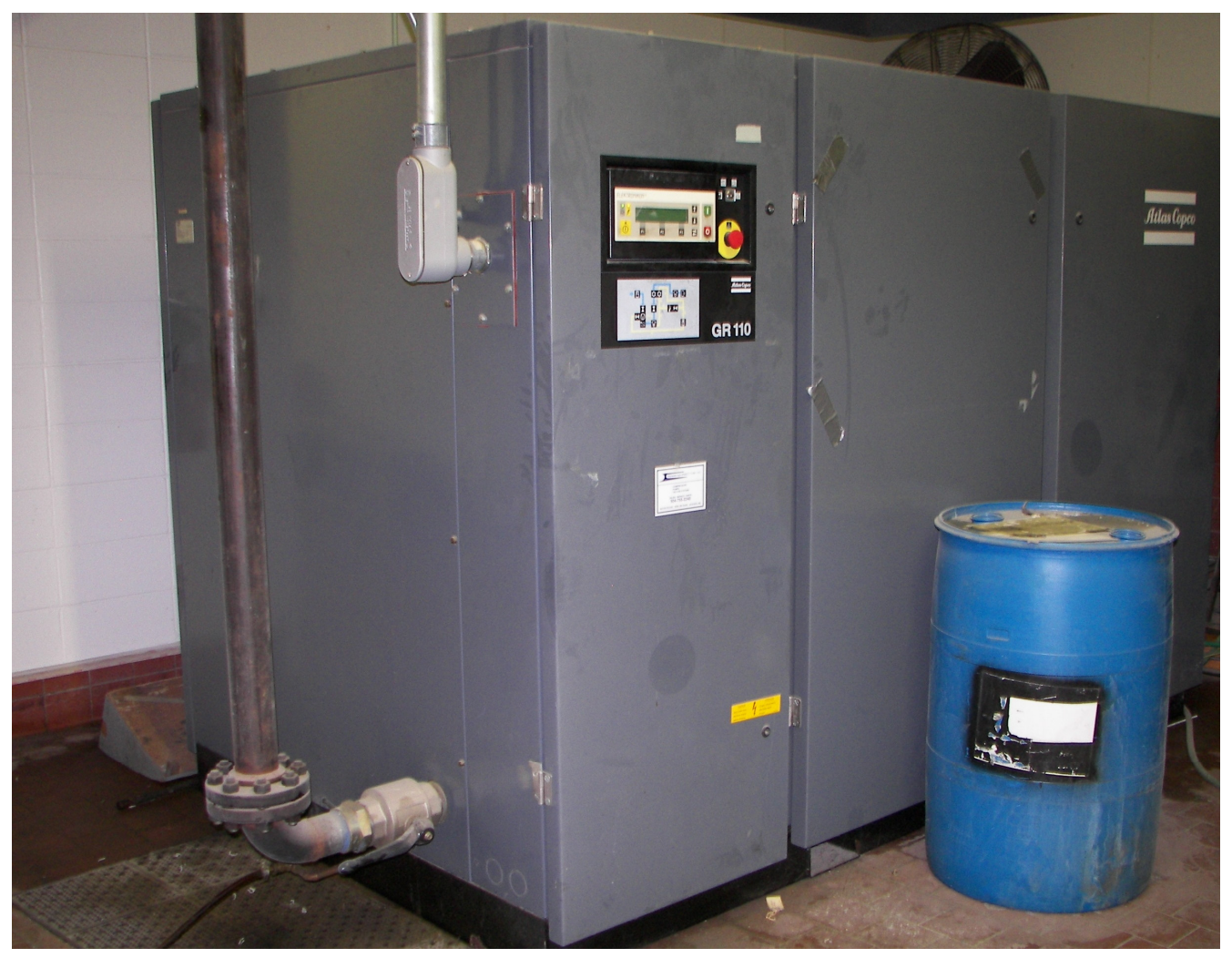

Figure 2.2: Atlas Copco GR 110 Two-Stage Screw Compressor

\subsection{Flow Metering}

The coolant air supply from the storage tank is routed to the test rig where it passes through a ball valve and a manual throttling valve. A panel mount rotameter with a maximum capacity of 60 SCFM is placed inline so as to meter the coolant flow entering the plenum and thus the film cooling holes. A flexible braided one inch diameter PVC hose is used to connect the outlet of rotameter to the coolant plenum. The air pressure at the rotameter inlet is $40 \mathrm{psi}$ and the outlet (the coolant plenum) is at atmospheric pressure. Figure 2.3 shows a picture of the rotameter. 


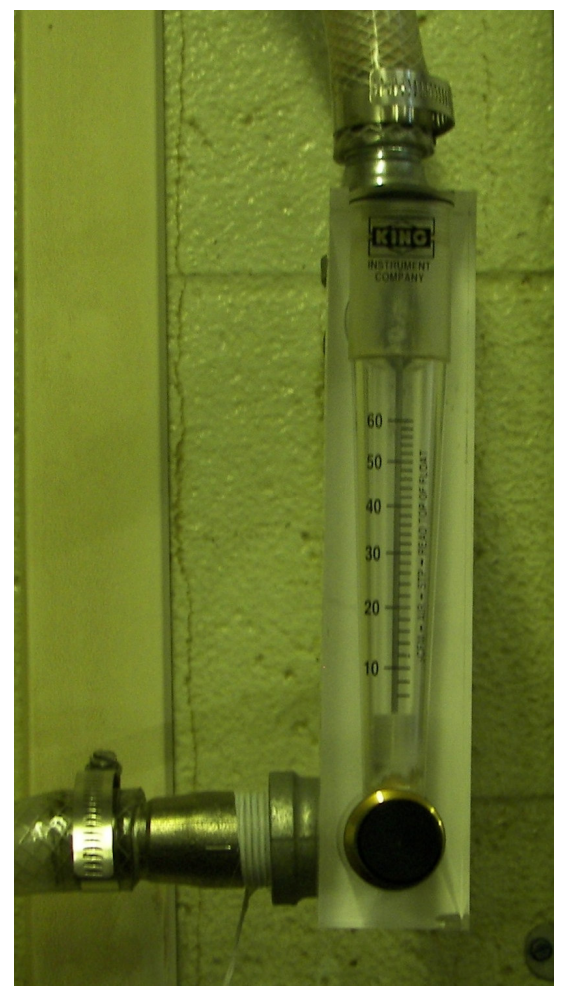

Figure 2.3: Rotameter with a maximum capacity of 60 SCFM

\subsection{Temperature Measurements}

In the experiment conducted, the temperature of the mainstream air, coolant air and the temperature of the test plate have to be measured.

\subsubsection{Thermocouples}

The mainstream and coolant air temperatures were recorded by type $-k$ thermocouples. The thermocouples were connected to an Omega instruNET analog to digital conditioning box. InstruNET software installed in a Pentium II computer was used to record the temperature. The system can be calibrated using a temperature simulator. Two 40 gage type $-k$ thermocouples were used to measure the temperature of hot mainstream air and cold coolant air.

\subsubsection{R Camera}

The surface temperature of the test plate was measured using an infrared thermography technique. The IR system used is a FLIR ThermaCAM SC 500. Figure 2.4 shows a picture of the 
IR camera. The camera offers a high quality, non intrusive method for obtaining thermal data through a commercially available software package for data analysis. The camera has a range of $-40^{\circ} \mathrm{C}$ to $500^{\circ} \mathrm{C}$. The ThermaCAM 500 utilizes uncooled microbolometer longwave detectors to sense IR radiation. This makes them ideal for general thermal measurement applications. The SC 500 system features real time 14-bit digital output, a 320 × 240 pixel detector, precision temperature measurement, internal data storage, and outstanding thermal sensitivity. The camera has the following specifications: the field of view and minimum focus distance are $24^{\circ} \times 18^{\circ}$ and $0.5 \mathrm{~m}$ respectively; the spectral range is 7.5 to $13 \mu \mathrm{m}$ and accuracy is $+/-2 \%$ or $2^{\circ} \mathrm{C}$. The test surface is viewed through a stretched polyurethane sheet. The sheet is thin enough to cause very little effect on IR transmissivity. The system calibration is conducted using a thermocouple placed on the black painted test surface to act as the benchmark. This thermocouple is used to estimate the emissivity of the test surface.

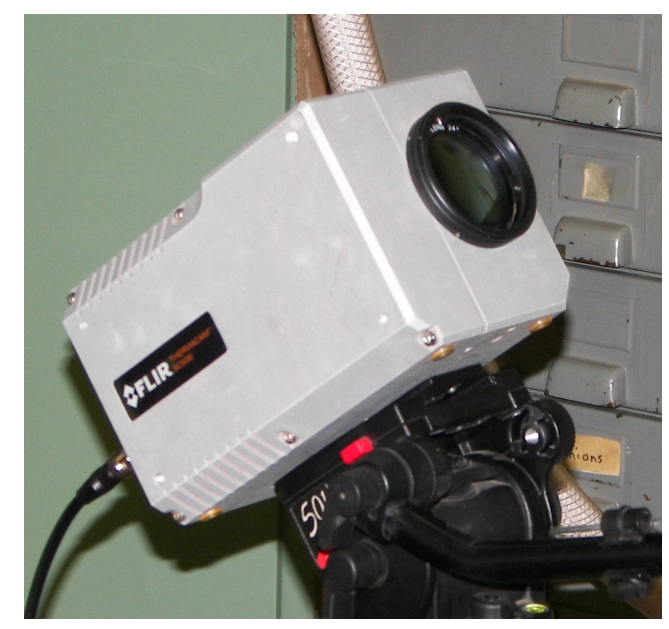

Figure 2.4: FLIR ThermaCAM SC 500 Infra Red Camera

The emissivity of the black painted test when viewed without the window is 0.96 . The calibrated transmissivity for the polyurethane sheet was 0.75 . Calibration was done at room temperature and the calibrated values remained fairly constant for the temperature range of the experiment $\left(22^{\circ} \mathrm{C}\right.$ to $\left.42^{\circ} \mathrm{C}\right)$. 


\subsection{Experimental Test Rig}

Figure 2.5 shows a comprehensive view of the test rig designed and built for the study.

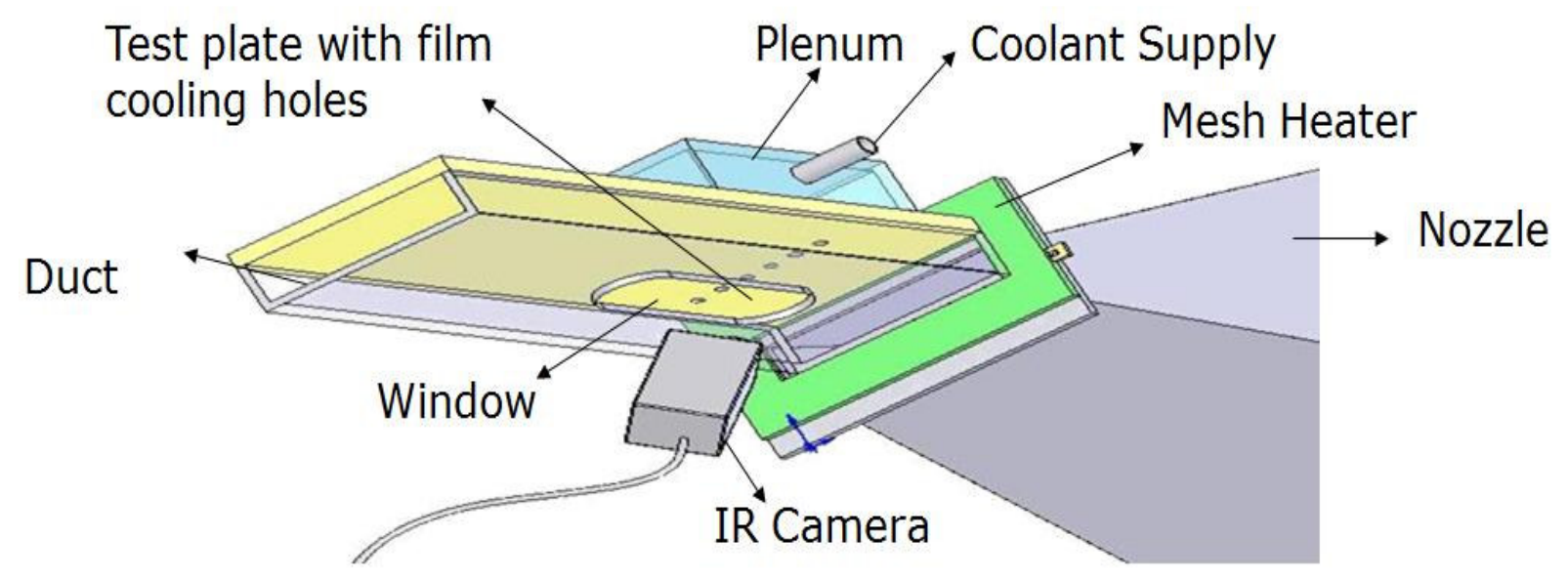

Figure 2.5: Overview of the Experimental Setup

A blower is used to intake the room temperature air, which is fed to a nozzle through a custom made GI duct. The nozzle is made up of gage 20 GI sheet. Its inlet is 28 inches by 23 inches and the exit is $13 \frac{1}{2}$ inches by $3 \frac{1}{2}$ inches. Its function is to increases the velocity of the mainstream air. The nozzle is attached to mesh heater by an acrylic flange. Mesh heater increases the temperature of the mainstream air from room temperature which is about $25^{\circ} \mathrm{C}$ to about $41^{\circ} \mathrm{C}$. A thermocouple is traversed to check the uniformity in temperature of the mainstream air after it is heated by the mesh heater. The mesh heater is attached to an acrylic duct through an acrylic flange. The duct is $3 \frac{1}{2}$ inches high, $13 \frac{1}{1 / 2}$ inches wide and 40 inches long. The top plate of the duct is made up of 1 inch thick ABS and has a rectangular slot at 10 inches downstream from the duct inlet. Flat coupons of film cooling test plate can be fitted in the slot. The coupons can be easily replaced so that the rig does not have to be dismantled for each of the test geometry. A trip is placed at the entrance to the test section to produce a fully turbulent boundary layer over the test plate. 
The coolant air is provided from a separate compressed air supply and is metered for flow measurement. Prior to the test the metered coolant air, through a three way ball valve is bypassed and is not allowed to enter the test section. When the test begins, ball valve is flipped and the coolant enters the plenum above the test plate and is then ejected through the film cooling holes into the test section. Thermocouples are mounted upstream of the film cooling holes in the duct to measure the mainstream temperature, and inside one of the film cooling holes to measure the coolant exit temperature. The coolant temperature is measured inside only one hole because pretesting showed that all film holes had the same flow rate and temperature conditions.

\subsubsection{Mesh Heater}

The heater is built with a 304 Stainless Steel woven wire mesh with a 20 micron wire diameter. The free area of the mesh was $33.6 \%$ which greatly reduced the free stream turbulence before the test section. Figure 2.6 shows the layout of mesh heater. The low electrical resistance of the dense wire mesh necessitated the use of a low voltage, high amperage power source. Power is supplied to the heater using a Miller Dialrc 250 AC/DC TIG welding machine. The heater provides a true step rise in the temperature of the mainstream air for the experimental needs. The mainstream temperature is monitored throughout the test. To obtain a desired temperature rise of about $18^{\circ} \mathrm{C}$ for the main stream air, two similar mesh heaters were connected in parallel and placed in line of the three and a half inches high and thirteen and a half inches wide test section.

To estimate the response time of the heater, an IR camera with a frame grabbing rate of $60 \mathrm{~Hz}$ was focused at the heater. As soon as the heater is flipped on, the steady temperature of the heater was seen in the next frame. Thus the response time of the heater is less than 16 milliseconds. 


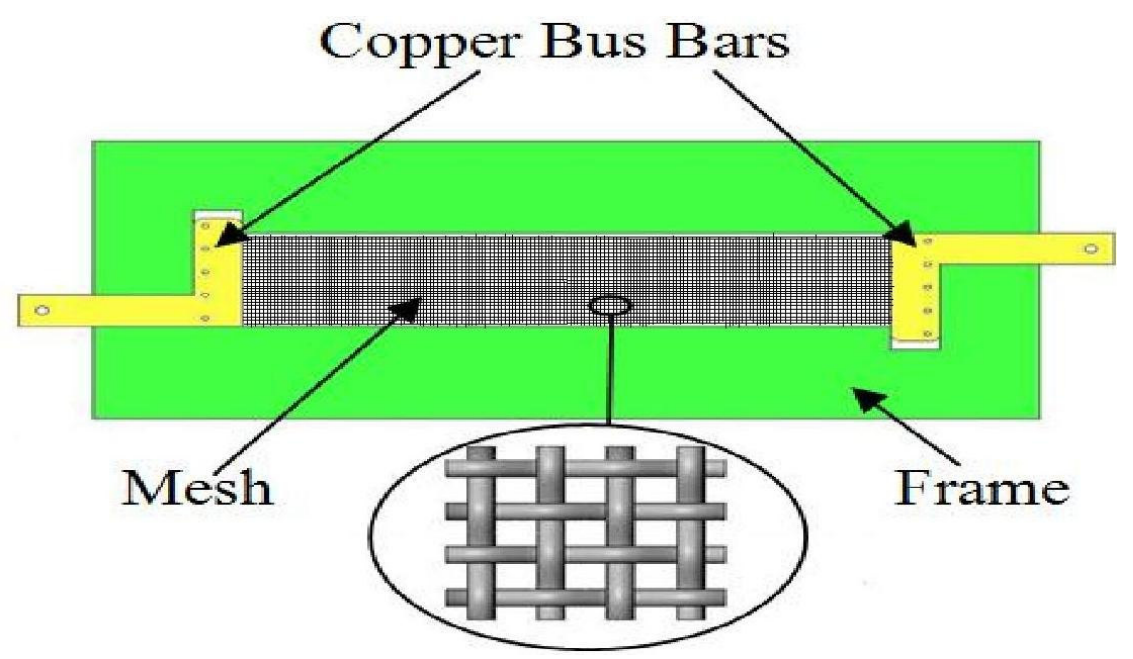

Figure 2.6: Mesh Heater

The thermal response of the heater measured with a 40 gage type $-k$ thermocouple is shown in the Figure 2.7.

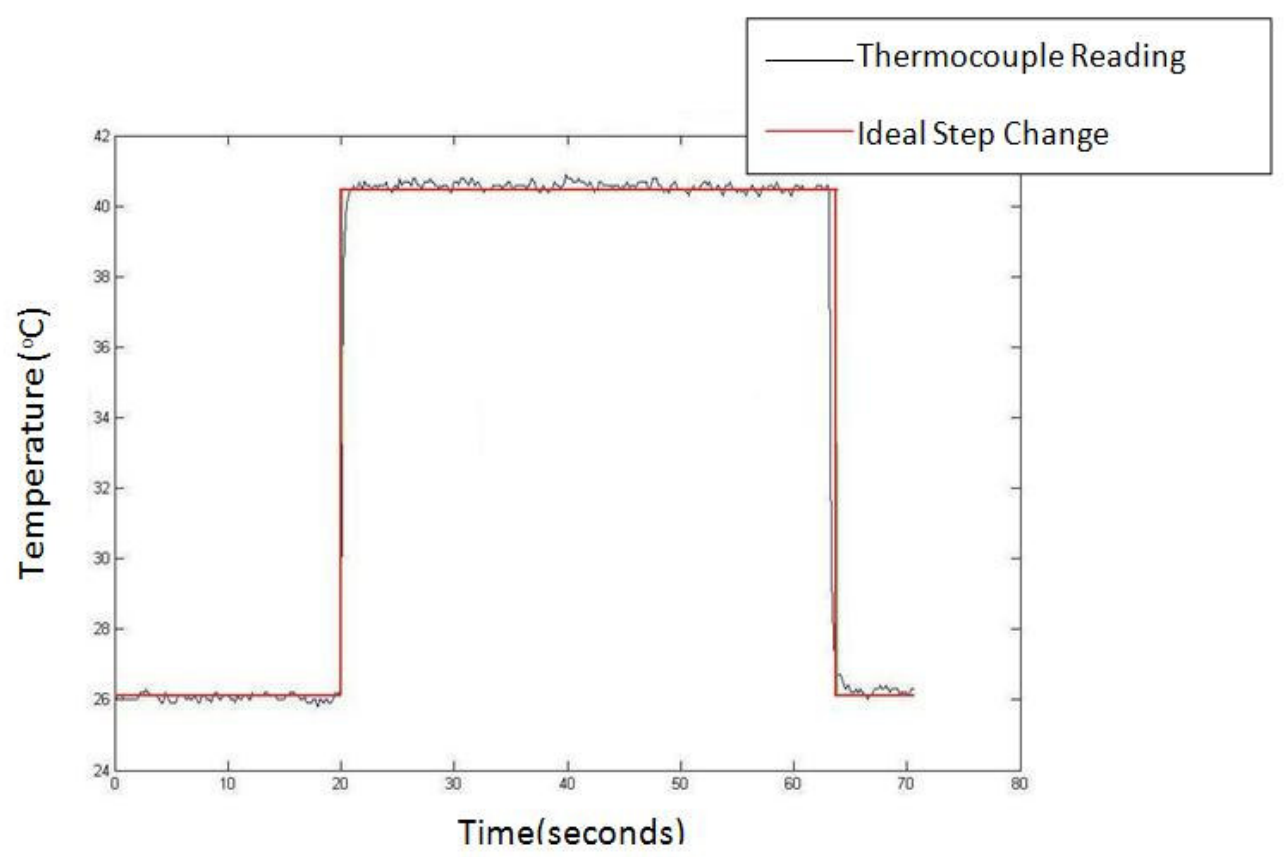

Figure 2.7: Thermal Response of Mesh Heater

\subsection{Film Cooling Hole Geometry}

A total of six different cases are studied. All the film cooling holes are provided with a pair of anti-vortex holes. Each case has a different anti vortex hole geometry and orientation. 
Each test plate has a total of six film cooling holes with a span wise spacing of three primary hole diameters. Data were collected from the two middle holes to reduce the effect of the side walls. The length in the stream wise direction was recorded as a ratio of the physical length to that of the primary hole diameter. The results of these cases were compared to a baseline case and a shaped hole case.

\subsubsection{Baseline}

The baseline case is a flat plate with six inclined holes as shown in the figure 2.8. The diameter of each hole is $1 / 2$ inch and the spacing between the holes is $1 \frac{1 / 2}{2}$ inches. The holes are inclined to the horizontal at an angle of $30^{\circ}$ along the flow direction.

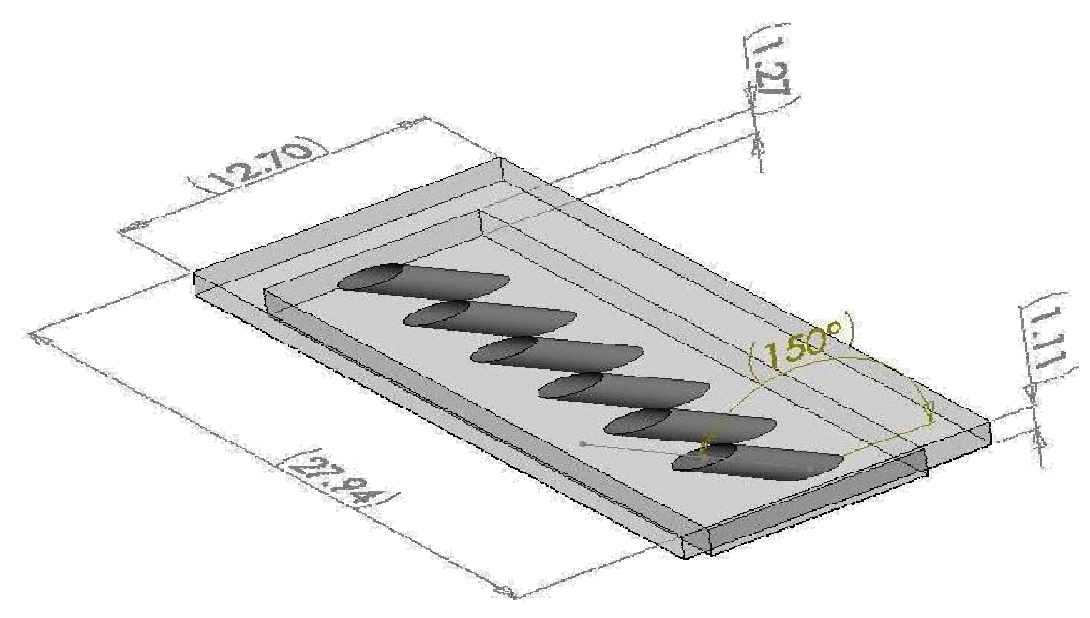

Figure 2.8: Baseline (dimensions in $\mathrm{cm}$ )

\subsubsection{Shaped Diffuser Holes}

The results of anti vortex holes are also compared to shaped diffuser holes. A shaped diffuser holes, because of its larger exit area reduces the velocity and the momentum of the coolant jet. Figure 2.9 shows the shaped hole configuration.|The hole inclination angle for the shaped diffuser hole is 30 degrees. The length of the cylindrical inlet portion is twice the diameter of the hole. The hole laid back angle is 15 degrees. The diffused exit angles at 20 degrees to the central axis. This is shown in figure 2.10. 


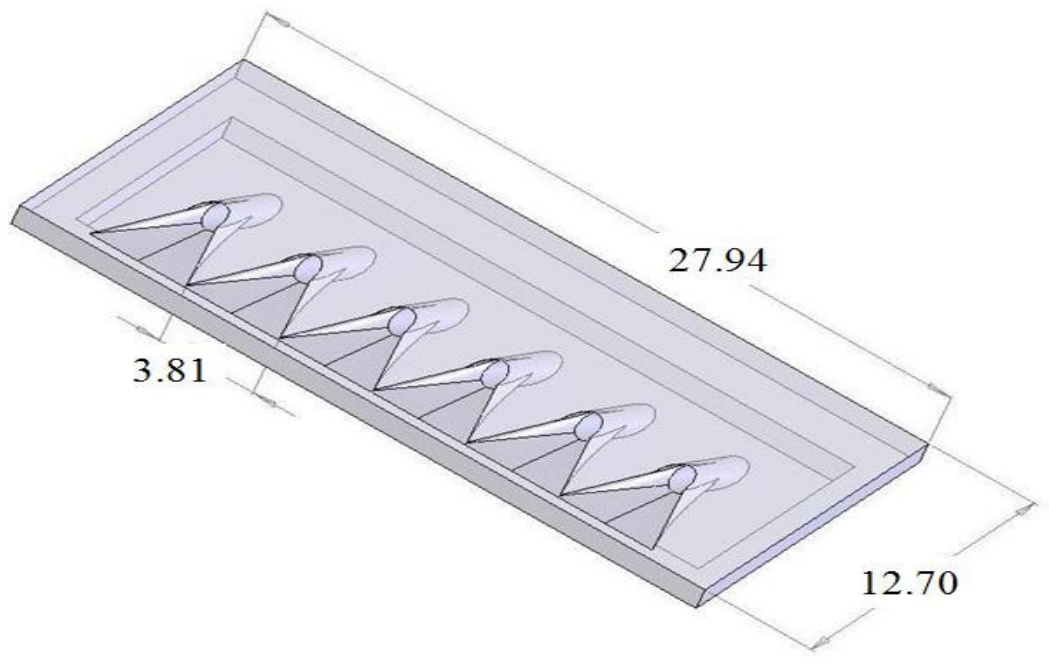

Figure 2.9: Shaped Diffuser Film Hole Configuration (dimensions in $\mathrm{cm}$ )

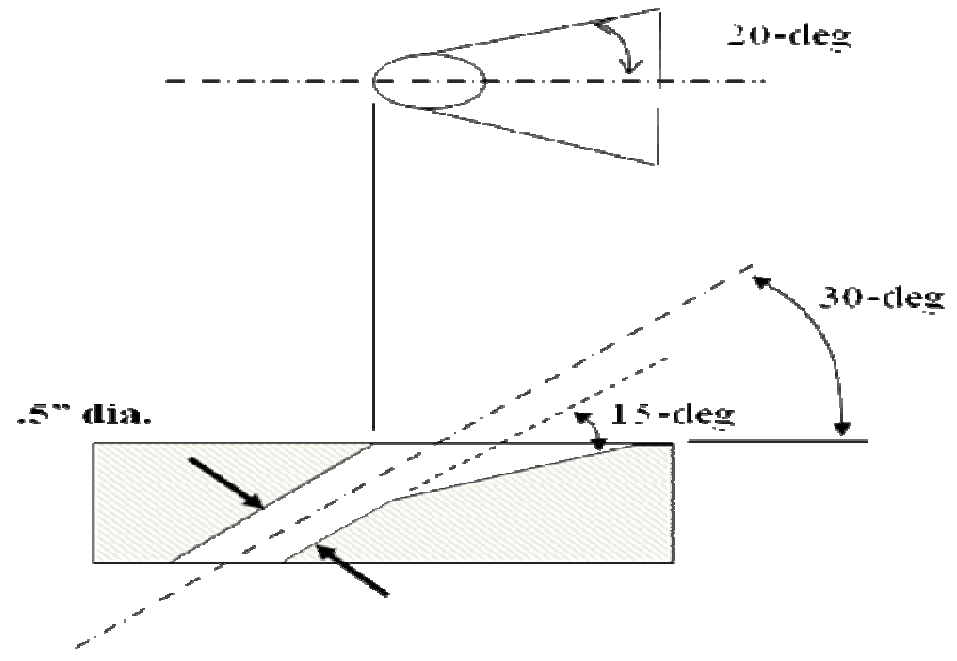

Figure 2.10: Top and Side Section View of Shaped Diffuser Hole

\subsubsection{Anti Vortex Holes}

A pair of anti vortex holes were added each to all the six film cooling holes. Figure 2.11 shows the test plate with the anti-vortex holes. The orientations and other geometries of the primary film cooling hole is the same as the baseline, only the features of the anti vortex film cooling holes are altered. Six different geometries are investigated. The details of the geometry are presented in figure 2.12. 


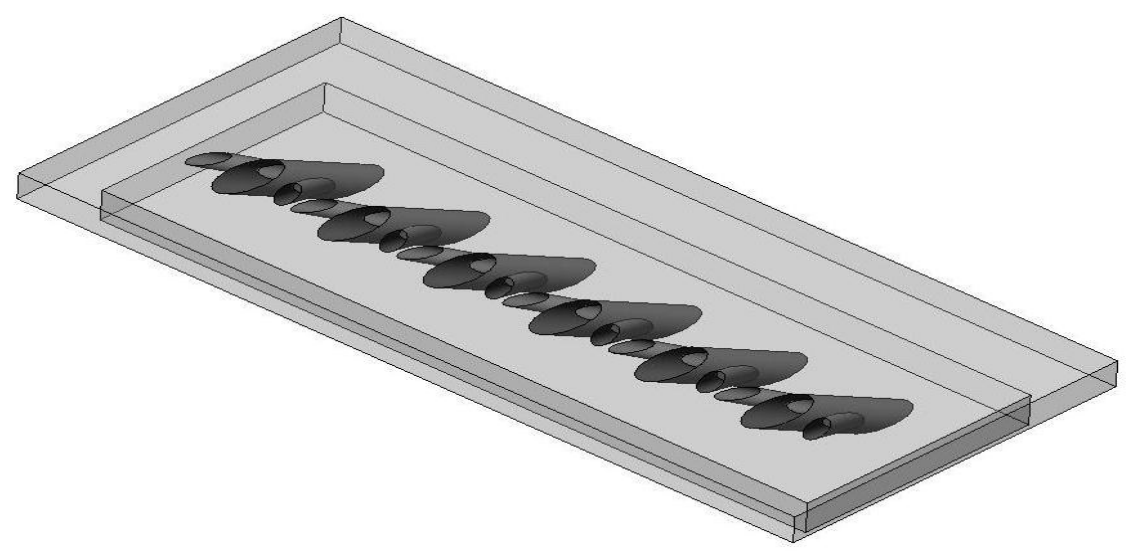

Figure 2.11: Test Plate with Anti Vortex Holes

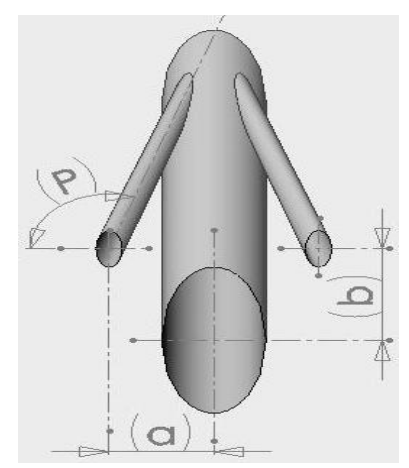

(a)

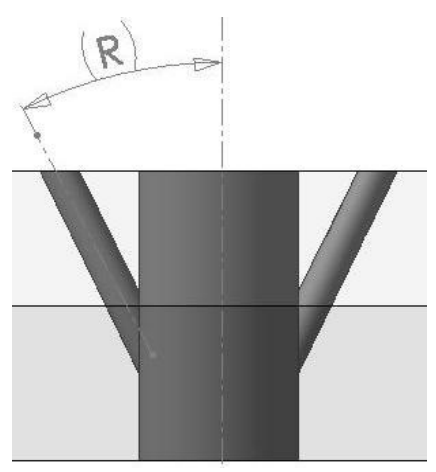

(b)

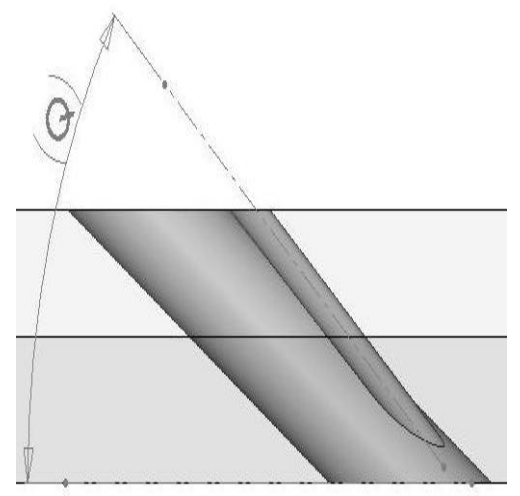

(c)

Figure 2.12: Top View (a), Front View (b) and Side View (c) of the Anti Vortex Hole Configuration

Figure 2.12 (a) shows the top view of the film cooling holes supplemented with a pair of anti vortex holes. The distance between the center of the anti vortex holes and the center of the primary film cooling holes measured in the $\mathrm{x}$ - direction is represented by parameter ' $\mathrm{a}$ '. The similar distance measured in the $y$ - direction is given by parameter ' $b$ '. The angle measured in degrees between the axis of the primary film cooling holes and the anti vortex holes measured in the horizontal plane is represented by parameter ' $\mathrm{P}$ '. Similar angles measured in the front vertical plane and the side vertical planes are represented by parameters ' $R$ ' and parameter ' $Q$ ' respectively. These angles are shown in Figure 2.12 (b) and Figure 2.12 (c). Parameter 'D' 
and' $d$ ' represents the diameters of the primary film cooling holes and the anti vortex holes respectively.

Figure 2.13 shows the first of the six anti vortex film cooling hole geometry to be investigated. The diameter of the primary film cooling hole is $1 / 2$ inches and the diameter of the anti vortex film cooling hole is $1 / 8$ inches. The exit of the anti vortex film cooling holes are upstream to the outlet of the primary film cooling hole. The anti vortex hole originate from the lower end of the primary film cooling hole. Both the anti vortex film cooling holes are symmetrical in orientation and location to the primary film cooling hole.

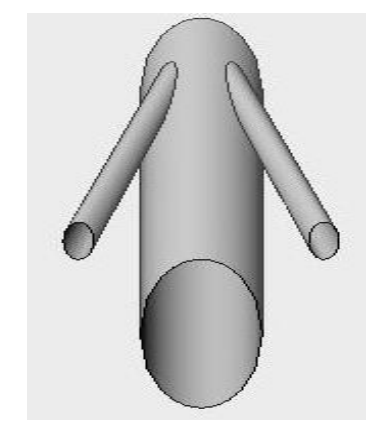

Figure 2.13: Anti Vortex Hole Orientation- Case 1

Figure 2.14 shows the second anti vortex film cooling hole geometry. The diameter of the anti vortex holes are $1 / 4$ inches and that of the primary film cooling holes are $1 / 2$ inches. The exit of the anti vortex film cooling hole geometry is in line with the primary film cooling holes. The anti vortex holes branch out from the middle of the primary film cooling holes.

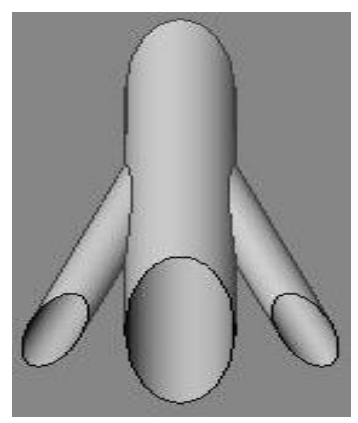

Figure 2.14: Anti Vortex Hole Orientation- Case 2 
Figure 2.15 shows the third geometry that was investigated. It is similar to case 2 , the only difference being the originating location of the anti vortex film cooling holes. They originate from the base region of the primary film cooling hole.

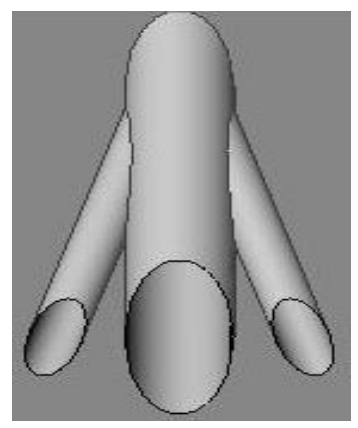

Figure 2.15: Anti Vortex Hole Orientation- Case 3

Figure 2.16 shows the fourth case that was studied. The diameters of the primary film cooling hole and anti vortex holes are $1 / 2$ inch and $1 / 4$ inches respectively.

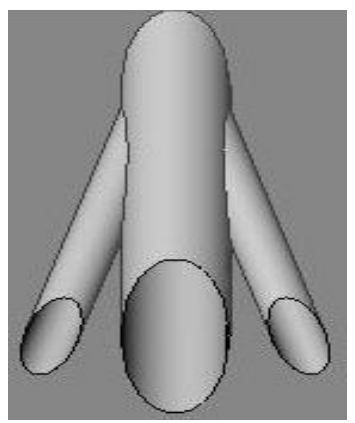

Figure 2.16: Anti Vortex Hole Orientation- Case 4

The difference in this case is that the exit of the anti vortex holes are downstream of the primary film cooling hole.

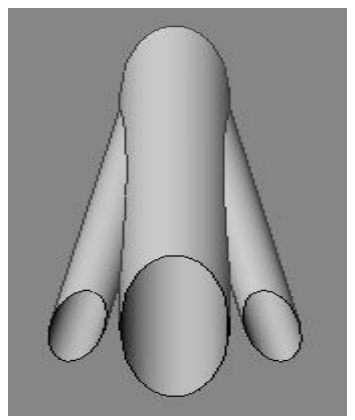

Figure 2.17: Anti Vortex Hole Orientation- Case 5 
Figure 2.17 shows the fifth case that was studied. The exits of the anti vortex holes are in line with the primary film cooling holes. The exit of the anti vortex holes are also notably nearer to the primary film cooling holes.

Figure 2.18 shows the last of the six cases that was studied. The diameter of the primary film cooling hole is $1 / 2$ inch and that of the anti vortex hole is $1 / 4$ inch. The anti vortex holes shoot out vertically upwards from the primary film cooling holes and thus the exit of the anti vortex holes is far upstream as compared to the exit of the primary film cooling hole.

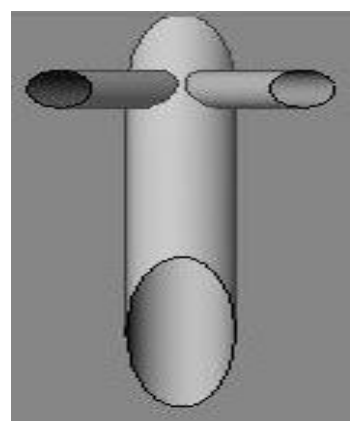

Figure 2.18: Anti Vortex Hole Orientation- Case 6

Table 1 outlines the geometric parameters and orientation of all 6 anti vortex holes. The parameters used are as explained above and the units are in centimeters and degrees.

Table 1: Test Plate Details

\begin{tabular}{|l|l|l|l|l|l|l|}
\hline & Case 1 & Case 2 & Case 3 & Case 4 & Case 5 & Case 6 \\
\hline $\mathrm{D}$ & 0.32 & 0.63 & 0.63 & 0.63 & 0.63 & 0.63 \\
\hline $\mathrm{D}$ & 1.27 & 1.27 & 1.27 & 1.27 & 1.27 & 1.27 \\
\hline $\mathrm{a}$ & 1.27 & 1.42 & 1.42 & 1.42 & 1.12 & 1.4 \\
\hline $\mathrm{b}$ & 1.6 & 0 & 0 & -0.56 & 0 & 4.12 \\
\hline $\mathrm{P}$ & 109.16 & 110.95 & 106.56 & 105.67 & 101.56 & 0 \\
\hline $\mathrm{Q}$ & 36.76 & 30 & 30 & 26.41 & 30 & 90 \\
\hline $\mathrm{R}$ & 24.95 & 34.74 & 27.21 & 27.91 & 19.43 & 30.62 \\
\hline $\begin{array}{c}\text { Start of anti } \\
\text { vortex } \\
\text { holes }\end{array}$ & $\begin{array}{c}\text { Lower } \\
\text { end of } \\
\text { main hole }\end{array}$ & $\begin{array}{c}\text { Mid of } \\
\text { main hole }\end{array}$ & $\begin{array}{c}\text { Lower } \\
\text { end of } \\
\text { main hole }\end{array}$ & $\begin{array}{c}\text { Lower } \\
\text { end of } \\
\text { main hole }\end{array}$ & $\begin{array}{c}\text { Lower } \\
\text { end of } \\
\text { main hole }\end{array}$ & $\begin{array}{c}\text { Lower } \\
\text { end of } \\
\text { main hole }\end{array}$ \\
\hline
\end{tabular}




\section{CHAPTER 3: EXPERIMENTAL METHODOLOGY}

This chapter will in detail explain the model used to determine the heat transfer coefficient and film cooling effectiveness for film cooling. The governing equations, boundary conditions, assumptions made and methodology used to solve the problems is described.

\subsection{Heat Transfer Theory}

\subsubsection{Heat Transfer Coefficient Measurement}

The test plate is modeled as an infinitely thick slab under a transient heat transfer phenomenon. Figure 3.1 shows a schematic of such a slab.

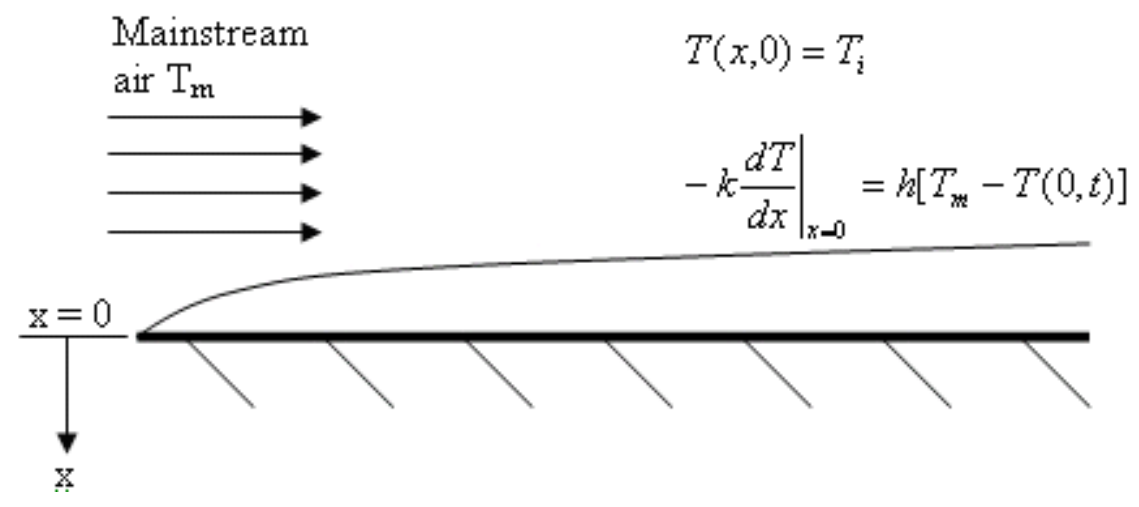

Figure 3.1: Flow over a Semi Infinite Slab

The slab is initially at a uniform temperature $T_{i}$ at time, $\mathrm{t}=0$. At time $\mathrm{t}>0$, the slab is suddenly exposed to a stream of hot air of temperature $T_{m}$. The hot stream of air provides a heat flux to the surface of the slab and convective heat transfer phenomenon occurs. Balancing thermal energy in the surface of the slab yields the following equations.

$$
\left(\frac{\partial^{2} T}{\partial x^{2}}+\frac{\partial^{2} T}{\partial y^{2}}\right)=\frac{1}{\alpha} \frac{\partial T}{\partial t}
$$

Neglecting the lateral conduction, equation 1 reduces to equation 2.

$$
\frac{\partial^{2} T}{\partial x^{2}}=\frac{1}{\alpha} \frac{\partial T}{\partial t}
$$


We need two boundary conditions and an initial condition to solve this partial differential equation. The initial condition is straight forward. At time, $t=0$, the slab is at initial temperature $T_{i}$. The first boundary condition is at the wall surface, i.e. at $x=0$. The boundary condition is derived from the thermal energy balance. The second boundary condition is at $x=\infty$. At such a depth, the thermal energy from the hot stream of air cannot penetrate the slab. Hence the other boundary of the wall remains unaltered in its temperature. These phenomena are represented by equations 3, 4 and 5 respectively.

$$
\begin{gathered}
T=T_{i} \text { at } t=0 \\
-k \frac{\partial T}{\partial x}=h\left(T_{w}-T_{m}\right) \text { at } x=0 \text { and } t \geq 0 \\
T=T_{i} \text { at } x=\infty \text { and } t \geq 0
\end{gathered}
$$

The variables used in these equations and boundary conditions are as follows.

$$
\begin{aligned}
& T_{w}=\text { Test surface wall temperature } \\
& T_{i}=\text { Test surface initial temperature } \\
& T_{m}=\text { Mainstream air temperature } \\
& k=\text { Thermal conductivity of test plate material } \\
& \alpha=\text { Thermal diffusivity of test plate material } \\
& t=\text { Time span for which hot mainstream air is blown } \\
& h=\text { Heat transfer coefficient }
\end{aligned}
$$

Solving the above partial differential equation with the prescribed initial condition and boundary conditions at $x=0$ gives the transient response of the test plate wall due to the convective heat load applied by the hot mainstream air. The solution is given by equation 6 [23].

$$
\frac{T_{w}-T_{i}}{T_{m}-T_{i}}=1-\exp \left(\frac{h^{2} \alpha t}{k^{2}}\right) \operatorname{erfc}\left(\frac{h \sqrt{\alpha t}}{k}\right)
$$


In the above equation, all the test plate properties are known. Thus recording $T_{w}$ at different time $t$, the value of heat transfer coefficient $h$ can be found out.

While deriving the above solution, the test slab was assumed to be semi infinitely thick. By this, it means that the test plate is a thick wall in which one end is exposed to a heat source and the other end is not affected by the boundary condition at the first end. This means the thermal pulse generated at one boundary doesn't reach the other end. The material property that dictates how fast a thermal pulse travels in a medium is the thermal diffusivity, $\alpha$. The depth to which the thermal pulse penetrates is a parameter dependent on the thermal diffusivity and the time to which the plate is exposed to the hot mainstream air, which is given by equation 7 .

$$
\text { Penetration Depth }=\sqrt{\alpha t}
$$

The test plate is made up of 1 inch thick ABS. ABS has a low thermal diffusivity and the test lasts for only 40 seconds. The penetration depth was found out to be less than $2 \mathrm{~mm}$. A thermocouple was stuck to one of the sides of the slab and hot mainstream air was blown past the other. The thermocouple reading remained unaltered, validating the semi infinite assumption. The other assumption made is that of one dimensional conduction which occurs only in the direction perpendicular to the wall. Since the penetration depth is small and the temperature gradient in the direction along the wall is relatively insignificant, the assumption seems valid for the experimental purpose.

\subsubsection{Film Cooling Effectiveness Measurement}

The heat transfer coefficient measurement is a two temperature problem, viz. the mainstream air temperature $\left(T_{m}\right)$ and the wall temperature $\left(T_{w}\right)$. When the coolant flows through the film cooling holes, unlike the heat transfer coefficient measurement, the problem is one involving three temperatures, viz., mainstream air temperature $\left(T_{m}\right)$, coolant temperature $\left(T_{c}\right)$ and the wall temperature $\left(T_{w}\right)$. 


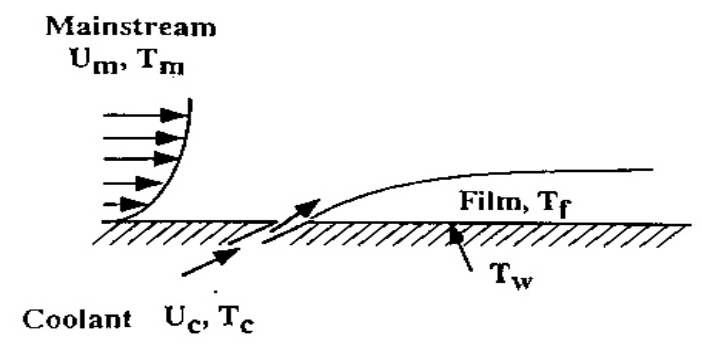

Figure 3.2: Schematic of Film Cooling Concept [24]

As seen in figure 3.2, in film cooling situation, it is the film which is the mixture of the main stream air and the coolant air that is responsible for the heat transfer to the test plate. Hence the mainstream temperature in equation 6 has to be replaced by the film temperature $\left(T_{f}\right)$. To determine the unknown film temperature $\left(T_{f}\right)$, a non dimensional temperature known as the film cooling effectiveness $(\eta)$ is defined. The definition is given by equation 8 .

$$
\eta=\frac{T_{f}-T_{m}}{T_{C}-T_{m}}
$$

The value of film cooling effectiveness $(\eta)$ ranges from 0 to 1 . When the film comprises only of coolant i.e., when the cooling is maximum, the value of $\eta$ is equal to 1 . When the film consists only of the mainstream air, i.e., when there is no coolant present at all, the value of $\eta$ is 0.Simplifying equation 8 we get equation 9 .

$$
T_{f}=\eta\left(T_{c}-T_{m}\right)+T_{m}=\eta T_{c}+(1-\eta) T_{m}
$$

Replacing $T_{m}$ in equation 6 by $T_{f}$ given by equation 9 , we get equation 10 .

$$
T_{w}-T_{i}=\left[1-\exp \left(\frac{h^{2} \alpha t}{k^{2}}\right) \operatorname{erfc}\left(\frac{h \sqrt{\alpha t}}{k}\right)\right] \times\left[\eta T_{c}+(1-\eta) T_{m}-T_{i}\right]
$$

This equation has two unknowns, film cooling effectiveness $\eta$ and heat transfer coefficient $h$ or if we refer to equation 6 , the two unknowns are $h$ and $T_{f}$. We need two sets of data points to solve for the unknowns. Noting the temperature of the wall $\left(T_{w}\right)$ at two different times, the value of unknowns can be determined. Thus in the transient test, if at time $t_{1}$ the surface is at temperature 
$T_{w 1}$ and at time $t_{2}$ the surface is at temperature $T_{w 2}$, then the two events are represented by equation 11.

$$
\begin{aligned}
& \frac{T_{w 1}-T_{i}}{T_{f}-T_{i}}=1-\exp \left(\frac{h^{2} \alpha t_{1}}{k^{2}}\right) \operatorname{erfc}\left(\frac{h \sqrt{\alpha t_{1}}}{k}\right) \\
& \frac{T_{w 2}-T_{i}}{T_{f}-T_{i}}=1-\exp \left(\frac{h^{2} \alpha t_{2}}{k^{2}}\right) \operatorname{erfc}\left(\frac{h \sqrt{\alpha t_{2}}}{k}\right)
\end{aligned}
$$

Measuring these two events at every point and solving equation 11 the value of $h$ and $T_{f}$ (and hence $\eta$ ) can be found out. This method is presented by Vedula and Metzger [25]. In the transient test, the mainstream will be heated and the coolant supply will be near room temperature. The wall temperatures are captured at set instants of time over the entire surface. Twenty separate events are recorded at an equal interval of 2 seconds and the wall temperatures at every surface location are obtained from the IR images. The mainstream temperature response is also measured. Equation 11 can be solved simultaneously even with only two known wall temperatures at the same locations and both unknowns $\mathrm{h}$ and $T_{f}$ can be determined. This has been demonstrated successfully by Ekkad et al. [26] for a single hole injecting coolant on to a leading edge model. In this study, all the twenty wall temperatures were used for a regression analysis that minimized the error while calculating $h$ and $\eta$ in a least squared sense so that the value determined had a best fit for all the data.

Along with the measurements of the film cooling effectiveness $\eta$ and heat transfer coefficient h, a new parameter known as the net heat flux ratio, defined by Ekkad et. al [16] is used to study their combined effect.Net heat flux ratio is the ratio of heat flux to the surface with film cooling to the heat flux without film cooling. Its definition is given by equation 12 .

$$
\frac{q^{\prime \prime}}{q_{0}^{\prime \prime}}=\frac{h}{h_{0}}\left(1-\frac{\eta}{\phi}\right)
$$


Where,

$$
\begin{aligned}
& h=\text { heat transfer coefficient with film cooling } \\
& h_{0}=\text { heat transfer coefficient without film cooling } \\
& \eta=\text { film cooling effectiveness } \\
& \phi=\text { overall cooling effectiveness, }\left(T_{f}-T_{c}\right) /\left(T_{m}-T_{c}\right) \\
& q^{\prime \prime}=\text { heat flux with film injection } \\
& q_{0}^{\prime \prime}=\text { heat flux without film holes }
\end{aligned}
$$

The overall cooling effectiveness, $\phi$ ranges between 0.5 and 0.7 for typical blade cooling systems. In this study, a typical value of 0.6 is chosen. If the value of this net heat flux ratio is less than 1.0, then the introduction of film cooling has beneficial effect in terms of reducing the heat load to the blade. If the value is greater than 1.0, it can be said that the film cooling did not serve its purpose of cooling the blades and in fact the heat load to the blade increases.

To study the effect of various amount of coolant flow for a fixed mainstream flow, another parameter known as the blowing ratio $(M)$ is defined. It is defined as the ratio of the mass flux of the coolant to the mass flux of the mainstream flow, which is given by equation 13.The higher the blowing ratio, the more is the coolant mass flux.

$$
\mathrm{M}=\frac{\rho_{c} U_{c}}{\rho_{m} U_{m}}
$$

Where,

$$
\begin{aligned}
& \rho_{c}=\text { Coolant Air Density } \\
& \rho_{m}=\text { Mainstream Air Density } \\
& U_{c}=\text { Coolant Air Velocity } \\
& U_{m}=\text { Mainstream Air Density }
\end{aligned}
$$




\subsection{Regression Analysis Method}

For the transient experiment considered, the parameters to be determined are $\mathrm{h}$ and $\eta$. It has already been said that measuring the wall temperature of the test surface $\left(T_{w}\right)$ at two different times, the values of $\mathrm{h}$ and $\eta$ can be obtained. The regression technique used to reduce uncertainty in experimental measurements was to collect multiple wall temperature-time data pairs over a broad range of temperatures to use in an over-constrained system of equations to solve for $h$ and $\eta$. The values of $h$ and $\eta$ are guessed and the wall temperature for all the times when the wall temperature is recorded by the IR Camera is calculated as per equation 10. The difference of this computed wall temperature and the wall temperate recorded with the IR camera gives the residual error.

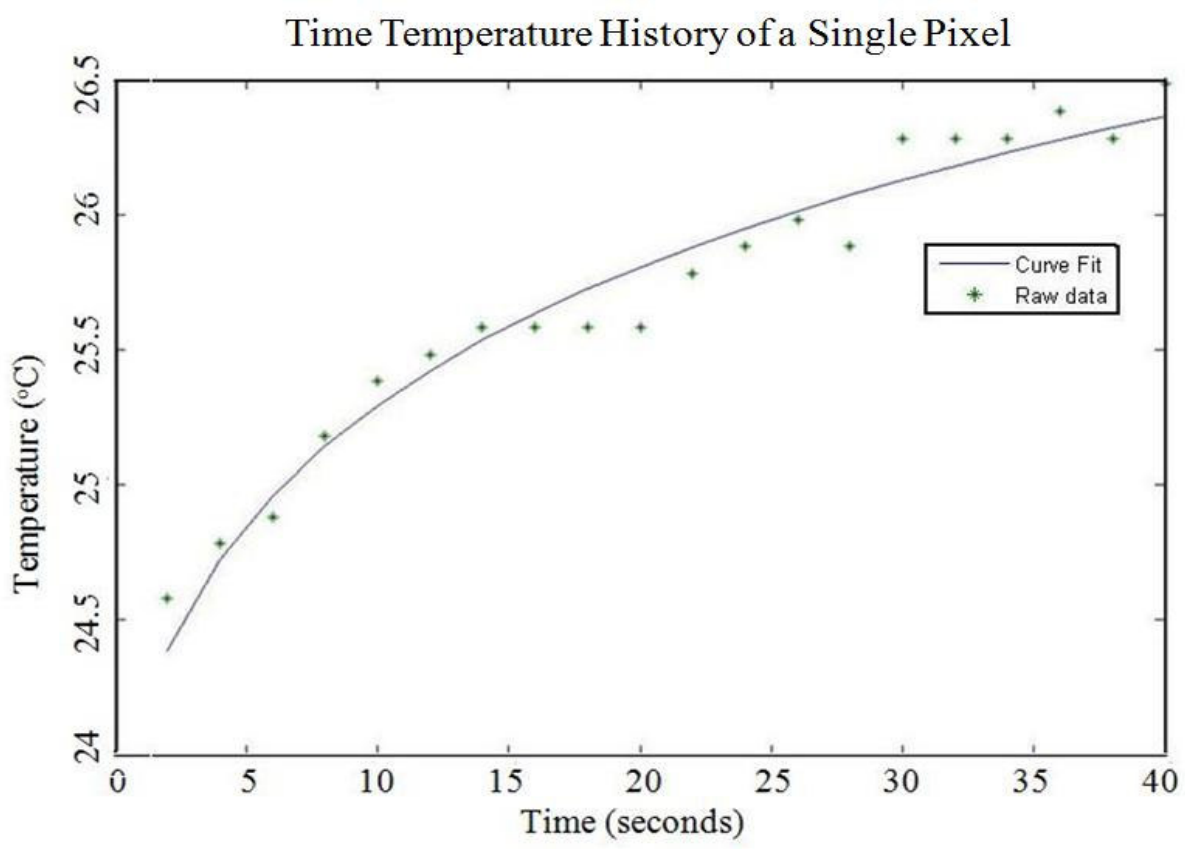

Fig 3.3: Curve Fit of Raw Data from a Single Pixel

The cumulative error for each pixel is computed as the square root of the sum of the residual error squared. This is shown in equation 14, where $e$ is the cumulative error.

$$
\left[\sum_{i=1}^{N}\left[\left.T_{w}(h, \eta)\right|_{t=t_{I R i}}-T_{I R i}\right]^{2}\right]^{1 / 2}=e(h, \eta)
$$


If this cumulative error is greater than a specified limit, the guess value of $h$ and $\eta$ are changed till the cumulative error is below the specified error limit. Thus it can be said that the residual error was minimized in a least squares sense solving for the heat transfer coefficient and film cooling effectiveness that best fit all data.

The regression method reduced the random IR camera read errors and also relaxes the dependence on the initial temperature of the test surface on the results. Figure 3.3 shows a typical time-temperature response of a single pixel and the best curve fit solution of the data.

\subsection{Uncertainty Analysis}

The accuracy of this study was determined by performing an error analysis using the methodology of Kline and McClintock [27]. First a conservative error estimate of the measured quantities was done. Then the relative uncertainties in measured quantities were calculated. Finally, the average uncertainties of the results were calculated by taking the square root of the summation of the square of all the relative uncertainties. The equation used to calculate the heat transfer coefficient, as described earlier is given by equation 15 .

$$
\frac{T_{w}-T_{i}}{T_{f}-T_{i}}=1-\exp \left(\frac{h^{2} \alpha t}{k^{2}}\right) \operatorname{erfc}\left(\frac{h \sqrt{\alpha t}}{k}\right)
$$

We can clearly see that the heat transfer coefficient $h$ is a function of wall temperature $\left(T_{w}\right)$, initial temperature $\left(T_{i}\right)$, film temperature $\left(T_{f}\right)$, thermal diffusivity $(\alpha)$ and thermal conductivity $(k)$

of the test plate and the time of the experiment. The film temperature in turn is a function of mainstream temperature $\left(T_{m}\right)$ and coolant temperature $\left(T_{c}\right)$. This is given by equation 16.

$$
h=\mathrm{f}\left(T_{w}, T_{i}, T_{m}, T_{c}, \alpha, k, t\right)
$$

The values of thermal diffusivity $(\alpha)$ and thermal conductivity $(k)$ are taken from the table. As a custom, three percent relative uncertainty is assumed for both variables. The relative uncertainties for the rest of the variables are given in equation 17. 


$$
\begin{aligned}
& U T_{w}=\Delta T_{w} / T_{w} \\
& U T_{i}=\Delta T_{i} / T_{i} \\
& U T_{m}=\Delta T_{w} / T_{w} \\
& U T_{c}=\Delta T_{c} / T_{c} \\
& U t=\Delta t / t \\
& U \alpha=U k= \pm 0.03
\end{aligned}
$$

Now, the root mean square uncertainty in calculating the value of heat transfer coefficient, $h$ for a film cooling case is given by equation 18 .

$$
U_{h}=\sqrt{\left(U T_{w}\right)^{2}+\left(U T_{i}\right)^{2}+\left(U T_{m}\right)^{2}+\left(U T_{c}\right)^{2}+\left(U_{t}\right)^{2}+\left(U_{\alpha}\right)^{2}+\left(U_{k}\right)^{2}}
$$

The value of $U_{h}$ was found out to be $3.9 \%$

Since the film cooling effectiveness was calculated using the heat transfer coefficient, while calculating the uncertainty of film cooling effectiveness, uncertainty associated with heat transfer coefficient has to be incorporated as well. The root mean square uncertainty in calculating film cooling effectiveness $(\eta)$ is given by equation 19 .

$$
U_{\eta}=\sqrt{\left(U_{h}\right)^{2}+\left(U T_{w}\right)^{2}+\left(U T_{i}\right)^{2}+\left(U T_{m}\right)^{2}+\left(U T_{c}\right)^{2}+\left(U_{t}\right)^{2}+\left(U_{\alpha}\right)^{2}+\left(U_{k}\right)^{2}}
$$

The value of $U_{\eta}$ was found out to be $4.5 \%$. 


\section{CHAPTER 4: RESULTS}

The measured mainstream velocity and free-stream turbulence using a calibrated single hot wire probe are $13.8 \mathrm{~m} / \mathrm{s}$ and $2 \%$ respectively. The mainstream Reynolds number $\left(\operatorname{Re}_{\mathrm{d}}\right)$ based on film hole diameter is 11000 . The boundary layer profile measured downstream of the trip is

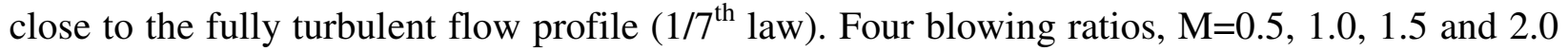
are tested for all the eight cases.

\subsection{Film Cooling Effectiveness}

Figure $4.1 \mathrm{a}, 4.1 \mathrm{~b}, 4.1 \mathrm{c}$ and $4.1 \mathrm{~d}$ show the effect of blowing ratio on detailed film effectiveness distributions for all the eight cases.

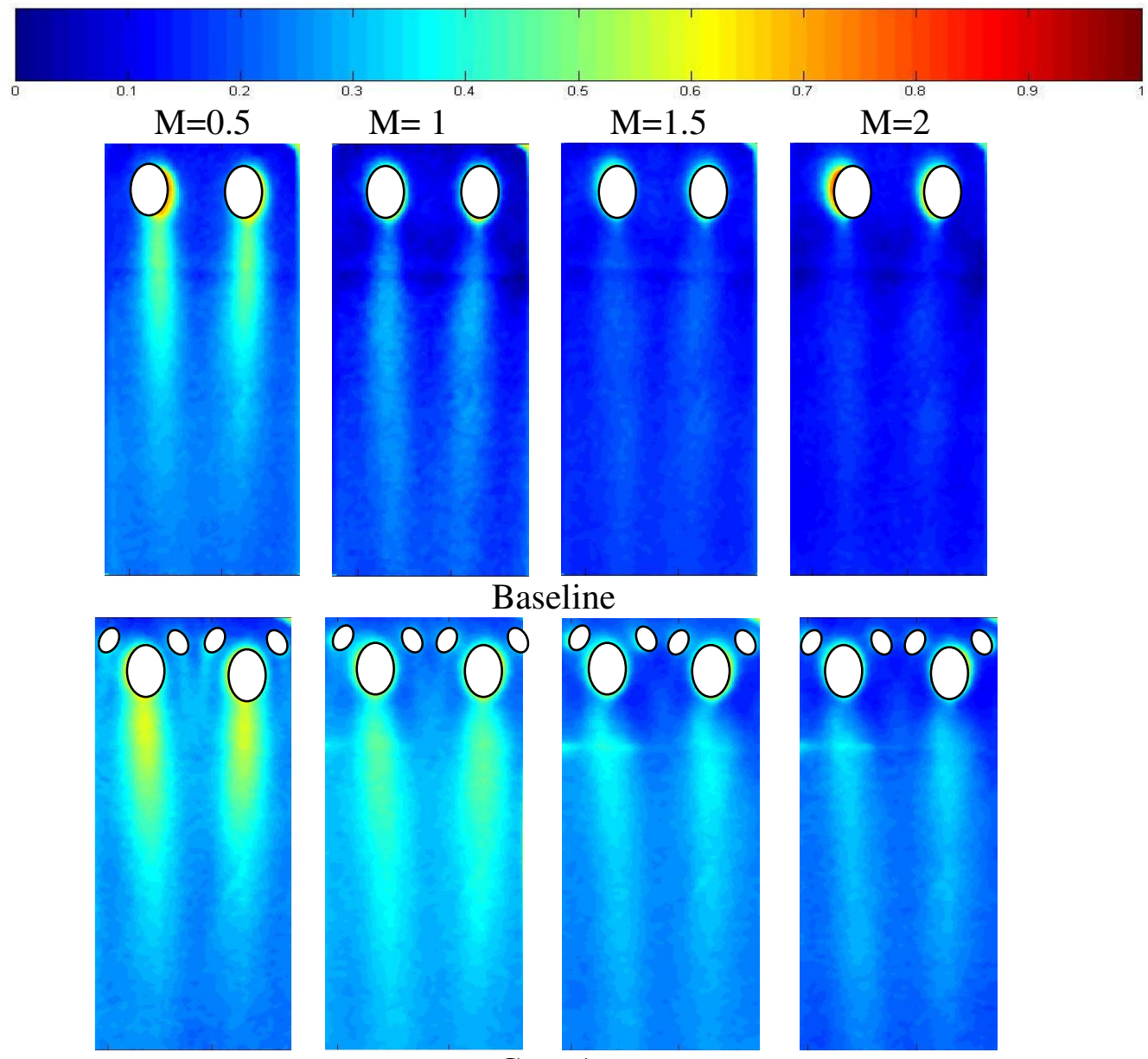

Case 1

Figure 4.1a: Detailed Film Cooling Effectiveness Distributions for Baseline and Case 1 at Different Blowing Ratios 
For the baseline case, the jet streaks are clearly visible with the highest effectiveness occurring at $\mathrm{M}=0.5$. At higher blowing ratios, there is a jet lift-off resulting in lower coverage. There is almost no film effectiveness for $M=2.0$. For case 1 , the anti vortex holes are $1 / 4$ the size of the main hole and exit upstream of the main hole. The trend is similar to baseline except for the higher effectiveness than baseline. The anti-vortex pair cause reduced flow through the main hole and also supplements the overall coverage in the region between the holes. It appears that the anti vortex holes produce a small but unsustainable vortex pair counter to the main vortex pair. It is clearly visible that the highest effectiveness occurs at blowing ratio of 0.5 . The effect of this anti-vortex pair appears to mainly reduce the coolant momentum flux from the main holes.

For case 2 , the anti vortex pair holes are $1 / 2$ the size of the main holes and the entry of the anti vortex pair is halfway into the main hole. The jet interactions from the two adjacent antivortex holes are very prominent. The best film cooling effectiveness is seen for blowing ratio 1 . The two holes from the adjacent anti-vortex pairs interact between the main holes and produce another jet streak similar to the main holes. Further downstream, the jet streaks coalesce and produce an almost uniform span wise effectiveness distribution. However, as the blowing ratio goes beyond $\mathrm{M}=1.0$, the effectiveness deteriorates rapidly.

In case 3, the anti vortex holes emerges out from the base of the main holes and are half the size of the main holes. Thus a more developed coolant flow can be expected from the anti vortex holes than case 2.The amount of coolant flowing out of the anti vortex holes can also be expected to be higher since the pressure difference between the inlet and the exit of the anti vortex holes would be close to that of the main film cooling holes. Higher effectiveness can be seen even for higher blowing ratios. The span wise and downstream coverage increases with blowing ratio. The only drawback is the region adjacent to the main holes which remains uncooled for higher blowing ratios. 


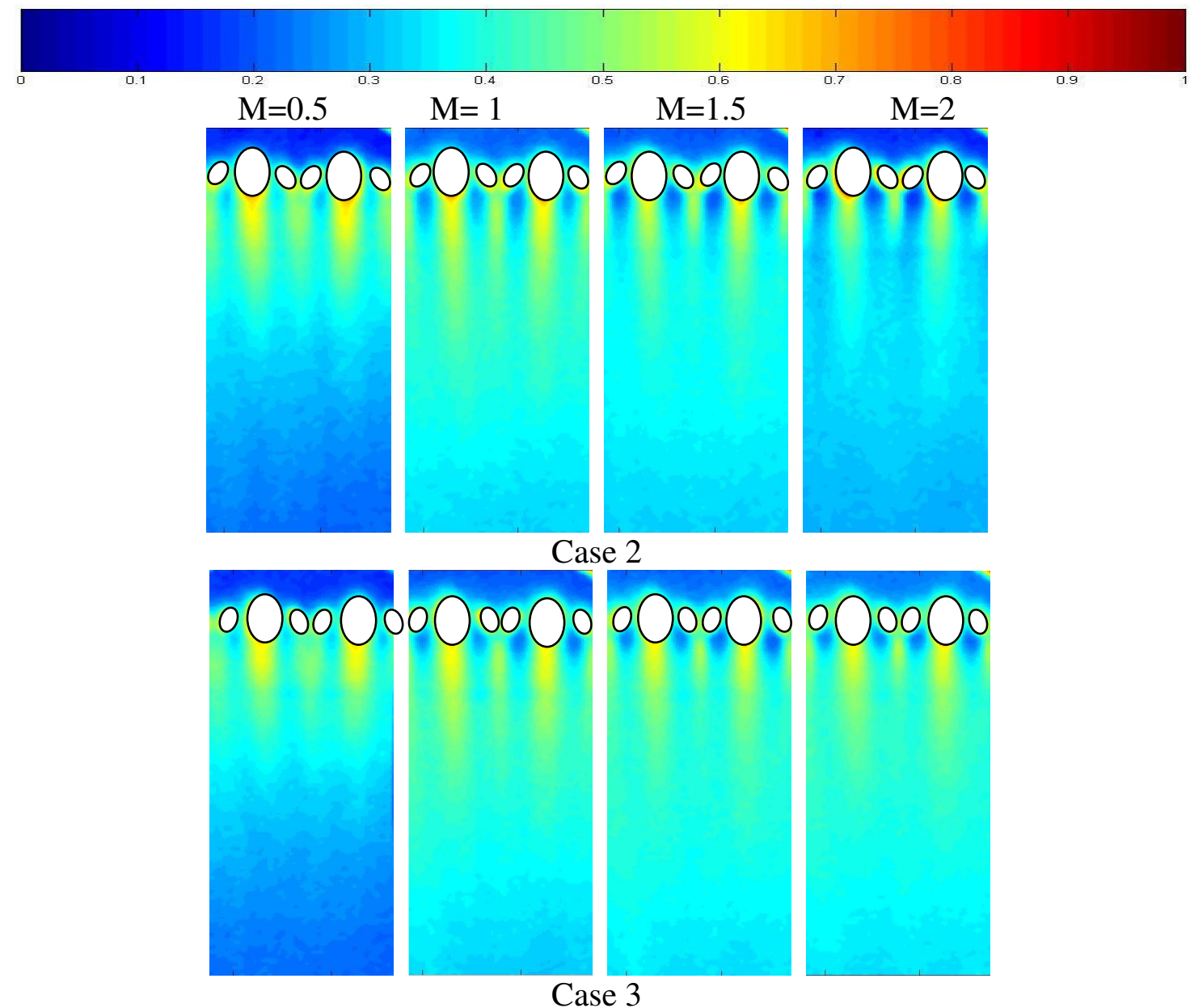

Figure 4.1b: Detailed Film Cooling Effectiveness Distributions for Case 2 and Case 3 at Different Blowing Ratios.

The case 4 is similar to case 3 except that the exit of anti vortex holes is farther downstream than for case 3. The result looks similar to that of case 3. Better attachment of the film jets to the surface can be seen even for higher blowing ratio. The additional length to the anti vortex pair holes does not provide significant benefits although there are some minor differences between cases 3 and 4 . case 5 has the exit of anti vortex holes very close to the main holes. The jets from the anti vortex holes mixes with that from the main holes for all blowing ratios and thus creates a thicker coolant streak footprint than all the other cases. However, the effectiveness distribution does not show a lateral spread as in cases 3-4. The effectiveness also appears to peak at $\mathrm{M}=1.5$ with similar levels at $\mathrm{M}=2.0$. 


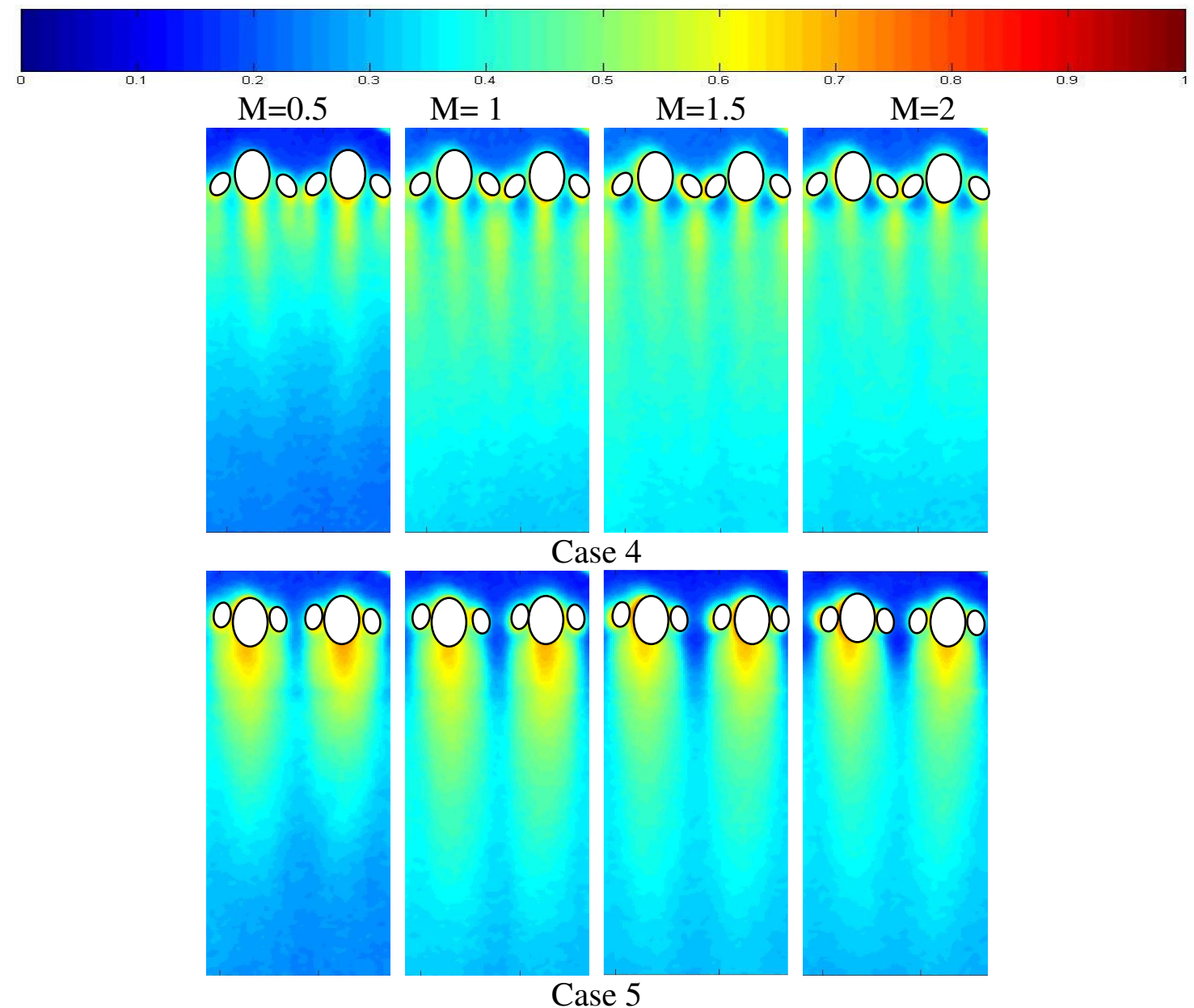

Figure 4.1c: Detailed Film Cooling Effectiveness Distributions for Case 4 and Case 5 at Different Blowing Ratios.

Case 6 has its anti vortex holes coming laterally outwards from the base of the main film cooling holes. At higher blowing ratio, the anti vortex jets seems to lift off clearly. But the presence of the anti vortex holes causes a decrement in the exit jet momentum from the main holes (due to less mass flow rate), thus restricting lift off even at blowing ratio of 1.5. This appears to cause effectiveness to be slightly better than baseline but does not contribute to significant effects as seen for cases 2 to 5 .

For shaped holes, the effectiveness distributions for blowing ratio of 1 and 1.5 indicate better lateral and downstream coverage. The larger exit area in shaped holes reduces the exit velocity of the coolant jet and hence the film remains adhered to the blade surface. At higher 
blowing ratio of 2 , the coolant jet however, has greater momentum to lift-off producing lower effectiveness than for $M=1.5$.

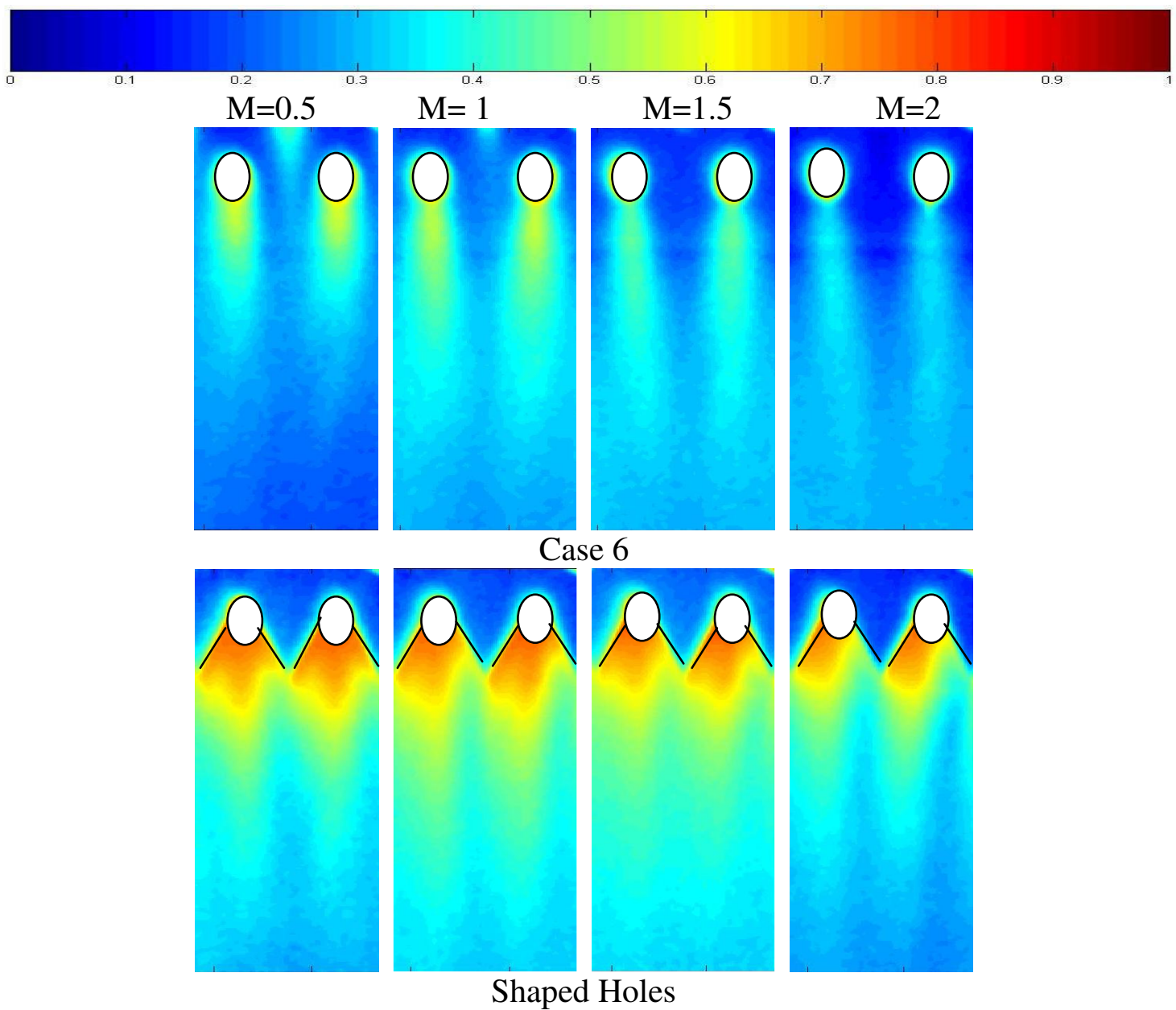

Figure 4.1d: Detailed Film Effectiveness Distributions for Case 6 and Shaped Holes at Different Blowing Ratios.

\subsection{Heat Transfer Coefficient}

Figure $4.2 \mathrm{a}, 4.2 \mathrm{~b}$, and $4.2 \mathrm{c}$ presents the effect of blowing ratio on detailed heat transfer coefficient $(h)$ distributions for the same eight cases. All the cases appear to enhance the heat transfer coefficient as compared to the baseline case. The area in the vicinity of the exit of primary and anti vortex coolant jets in the downstream region appears to have high heat transfer coefficient. This is due to the result of interaction between the jet (both primary and anti vortex) and the main stream which produces region of high turbulence. 

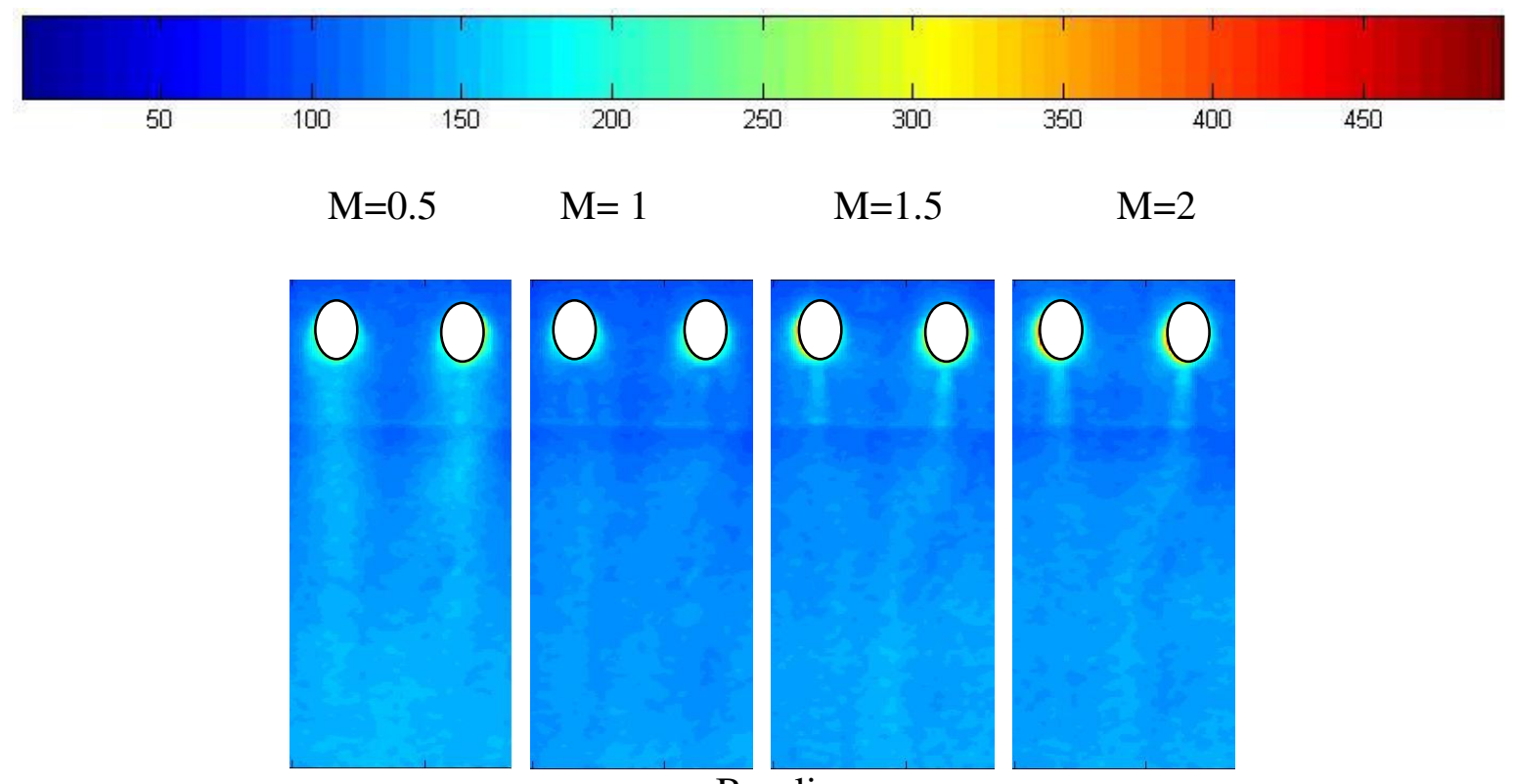

Baseline
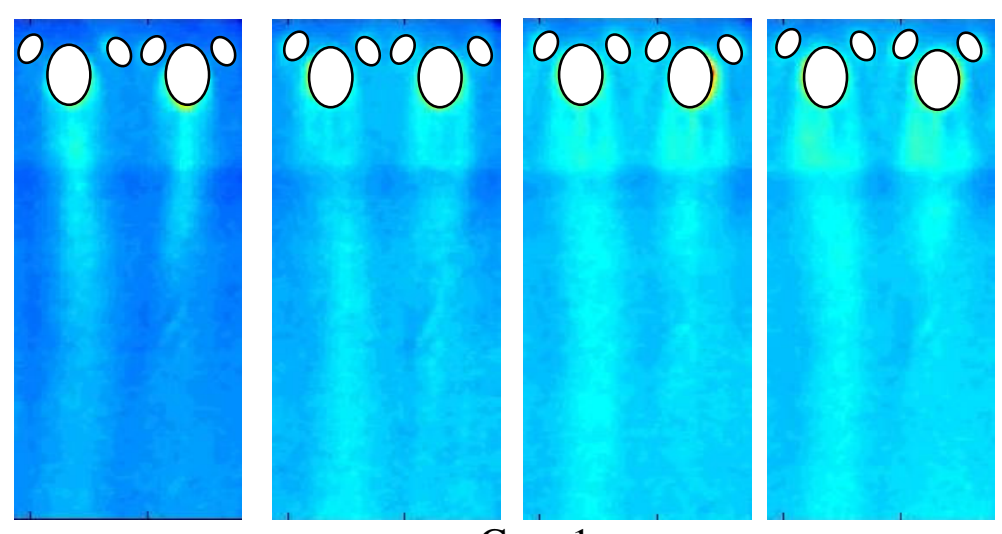

Case 1
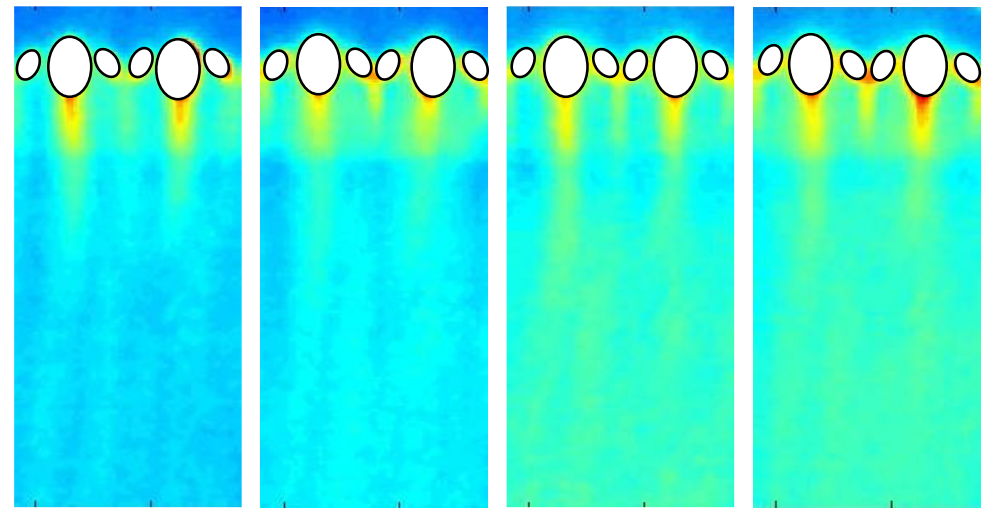

\section{Case 2}

Figure 4.2a: Detailed Heat Transfer Coefficient $\left(\mathrm{W} / \mathrm{m}^{2} \mathrm{~K}\right)$ Distributions for Baseline, Cases 1 and 2 at Different Blowing Ratios 

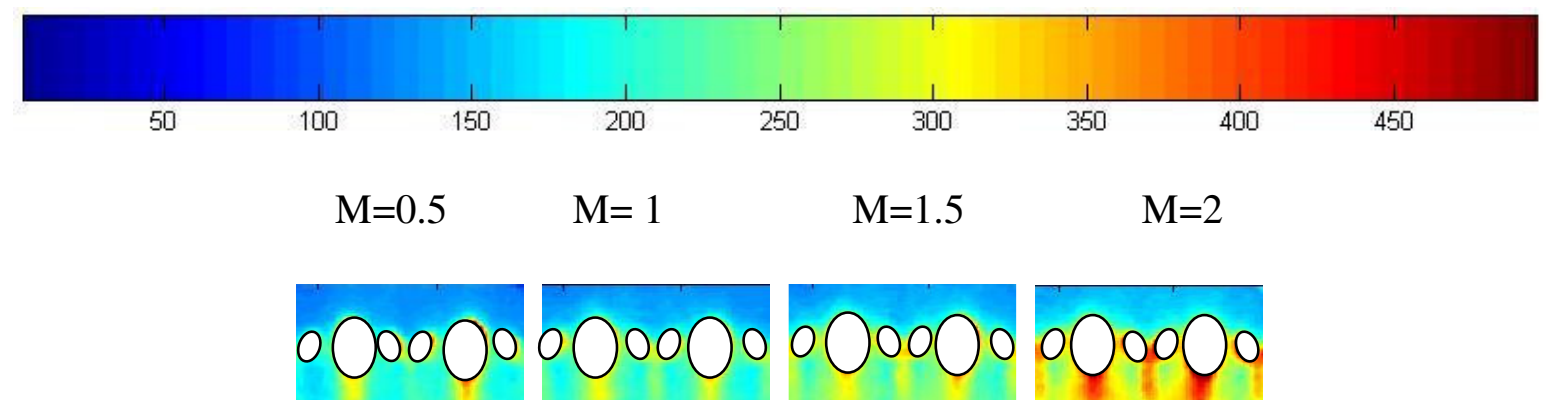

Case 3
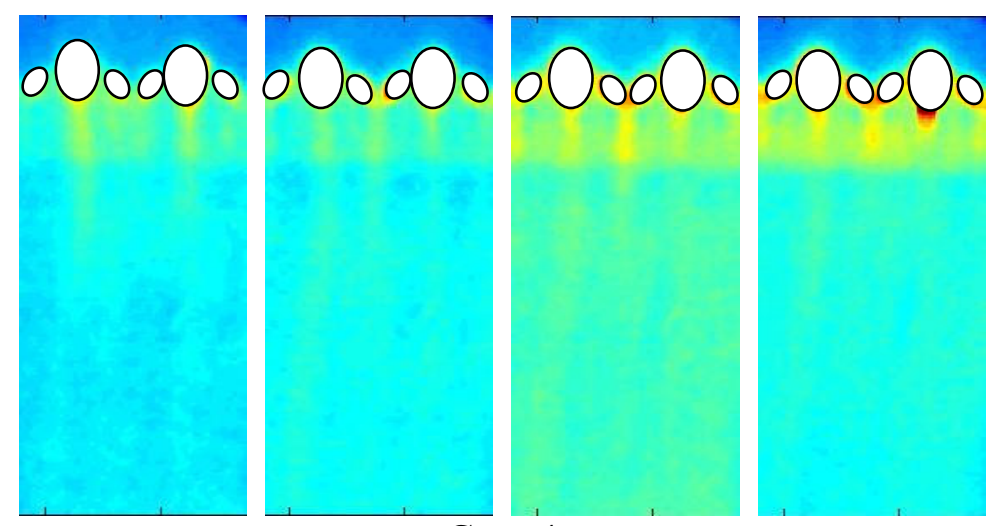

Case 4
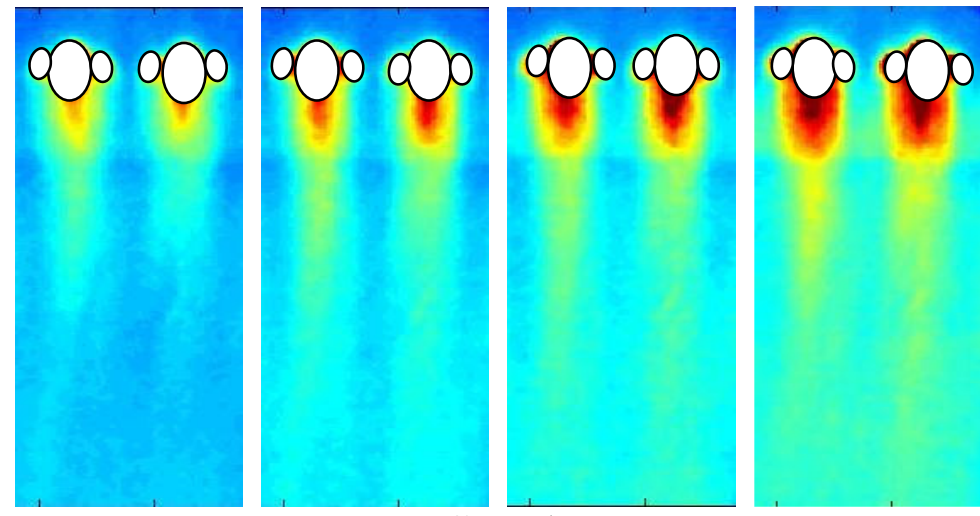

Case 5

Figure 4.2b: Detailed Heat Transfer Coefficient $\left(\mathrm{W} / \mathrm{m}^{2} \mathrm{~K}\right)$ Distributions for Cases 3, 4 and 5 at Different Blowing Ratios 


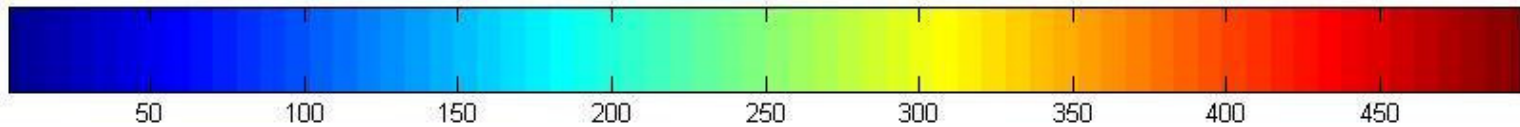

$$
\mathrm{M}=0.5 \quad \mathrm{M}=1 \quad \mathrm{M}=1.5 \quad \mathrm{M}=2
$$
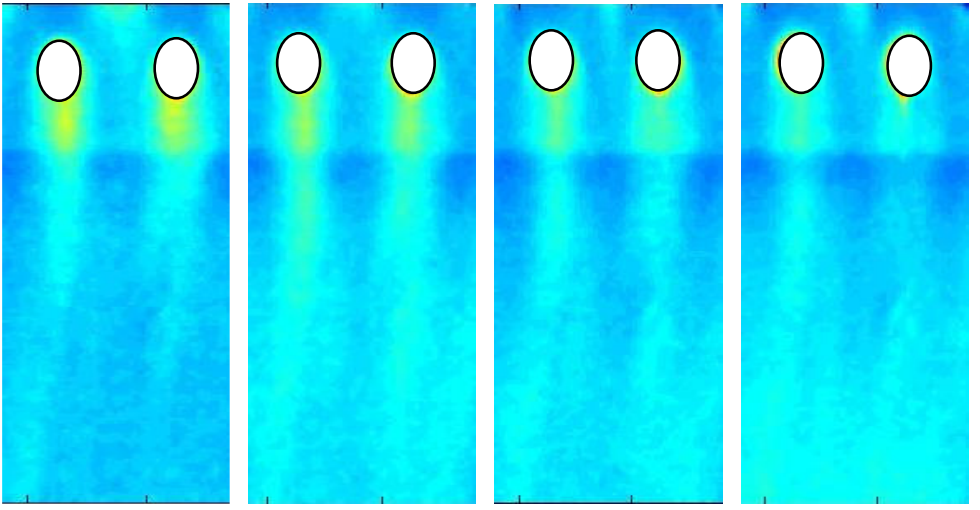

Case 6
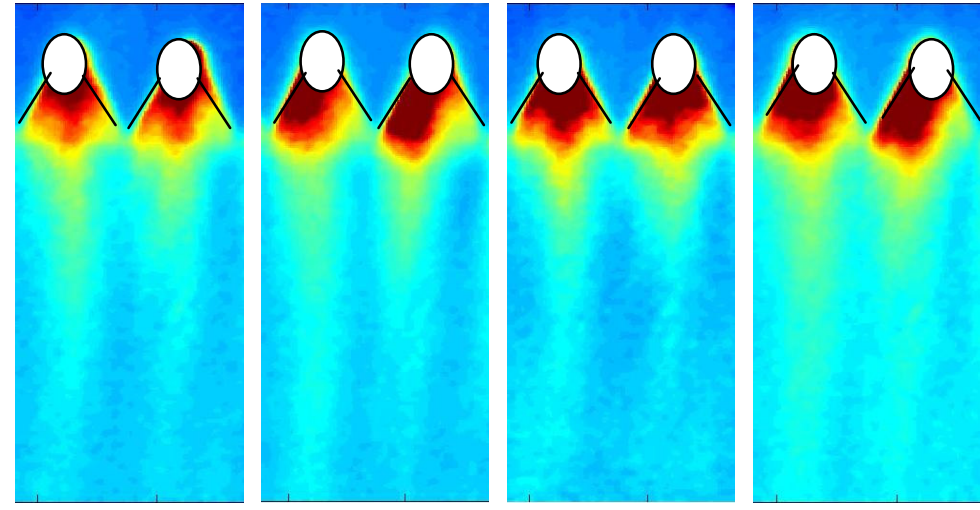

Shaped Holes

Figure 4.2c: Detailed Heat Transfer Coefficient $\left(\mathrm{W} / \mathrm{m}^{2} \mathrm{~K}\right)$ Distributions for Case 6 and Shaped Holes at Different Blowing Ratios

Except for cases where there is lift off of the coolant jet, the high heat transfer coefficient region seems to extend far downstream. It appears that case 5 enhances heat transfer coefficient the most because of the strong interaction between the anti vortex pair and the main hole.

\subsection{Spanwise Averaged Film Cooling Effectiveness}

Figures $4.3 \mathrm{a}, 4.3 \mathrm{~b}$ and $4.3 \mathrm{c}$ presents the effect of anti vortex hole geometry and orientations on spanwise averaged film effectiveness for each blowing ratio. The downstream exit point of the primary hole is at the location $\mathrm{x} / \mathrm{D}=2$ and that for shaped holes is $\mathrm{x} / \mathrm{D}=5$. 


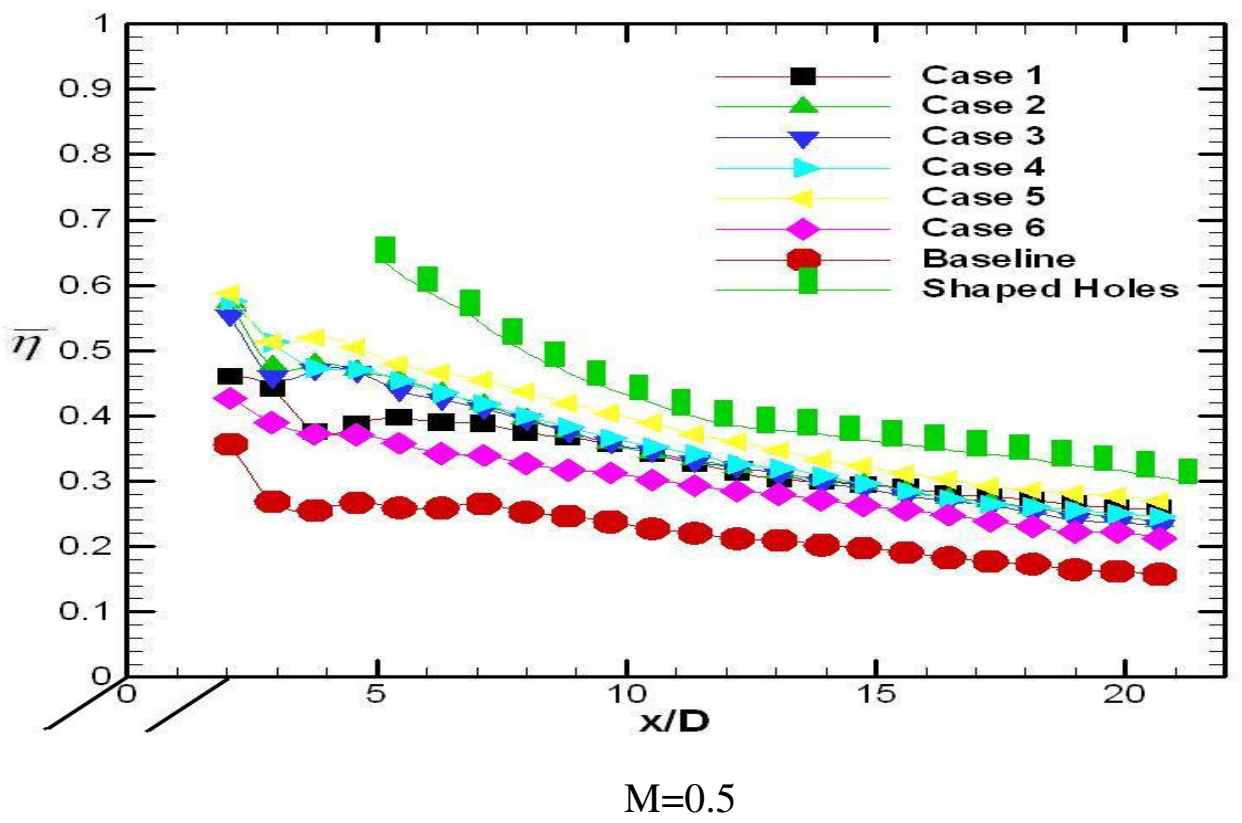

Figure 4.3a: Effect of Anti Vortex Hole Geometry on Spanwise Averaged Film Cooling Effectiveness Distributions at Blowing Ratio 0.5

At low blowing ratio of $\mathrm{M}=0.5$, case 5 with the exit of the anti vortex holes near the primary holes, clearly provides the highest effectiveness after shaped holes. Effectiveness of cases 1, 2, 3 and 4 are also relatively higher than the baseline. Case 6 has the lowest relative effectiveness, better than only baseline.

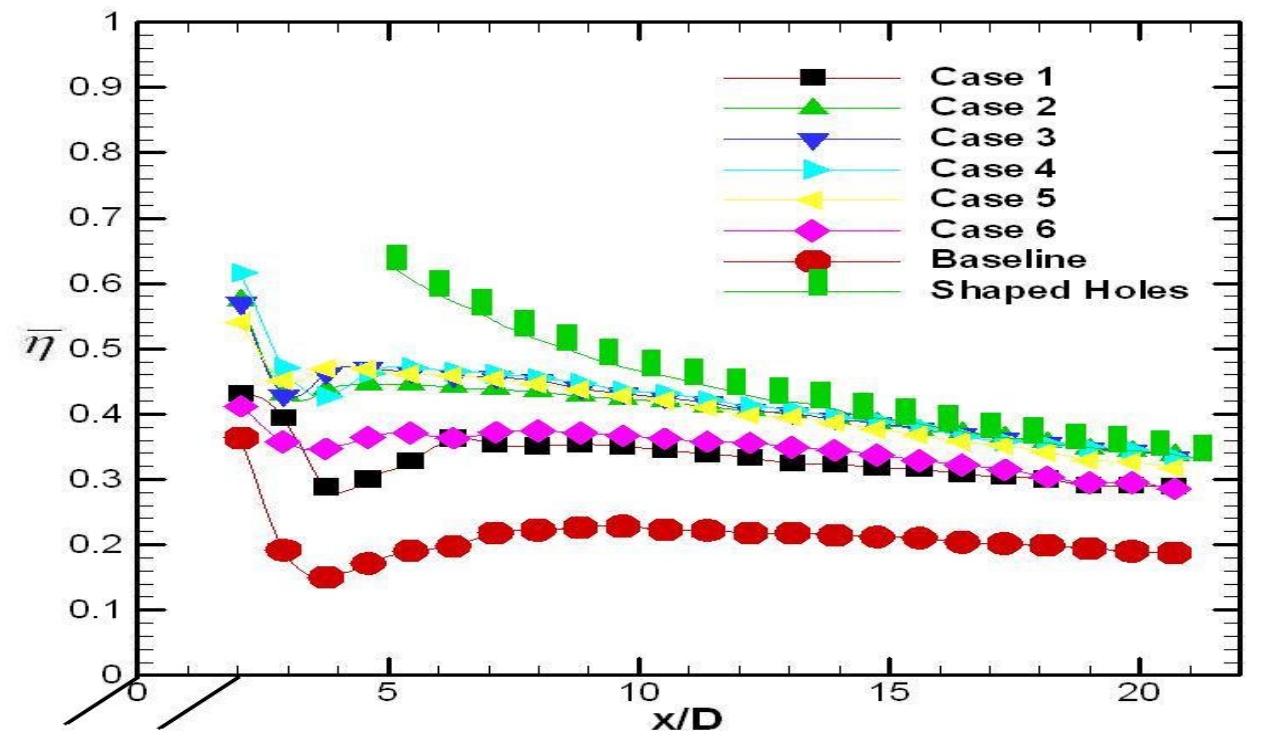

$$
\mathrm{M}=1.0
$$

Figure 4.3b: Effect of Anti Vortex Hole Geometry on Spanwise Averaged Film Cooling Effectiveness Distributions at Blowing Ratio 1.0 
As blowing ratio increases to $\mathrm{M}=1.0$, the effectiveness of cases $2,3,4$ and 5 are almost identical which is below only shaped holes. The film cooling effectiveness of case 1 is lower than for case 6 .
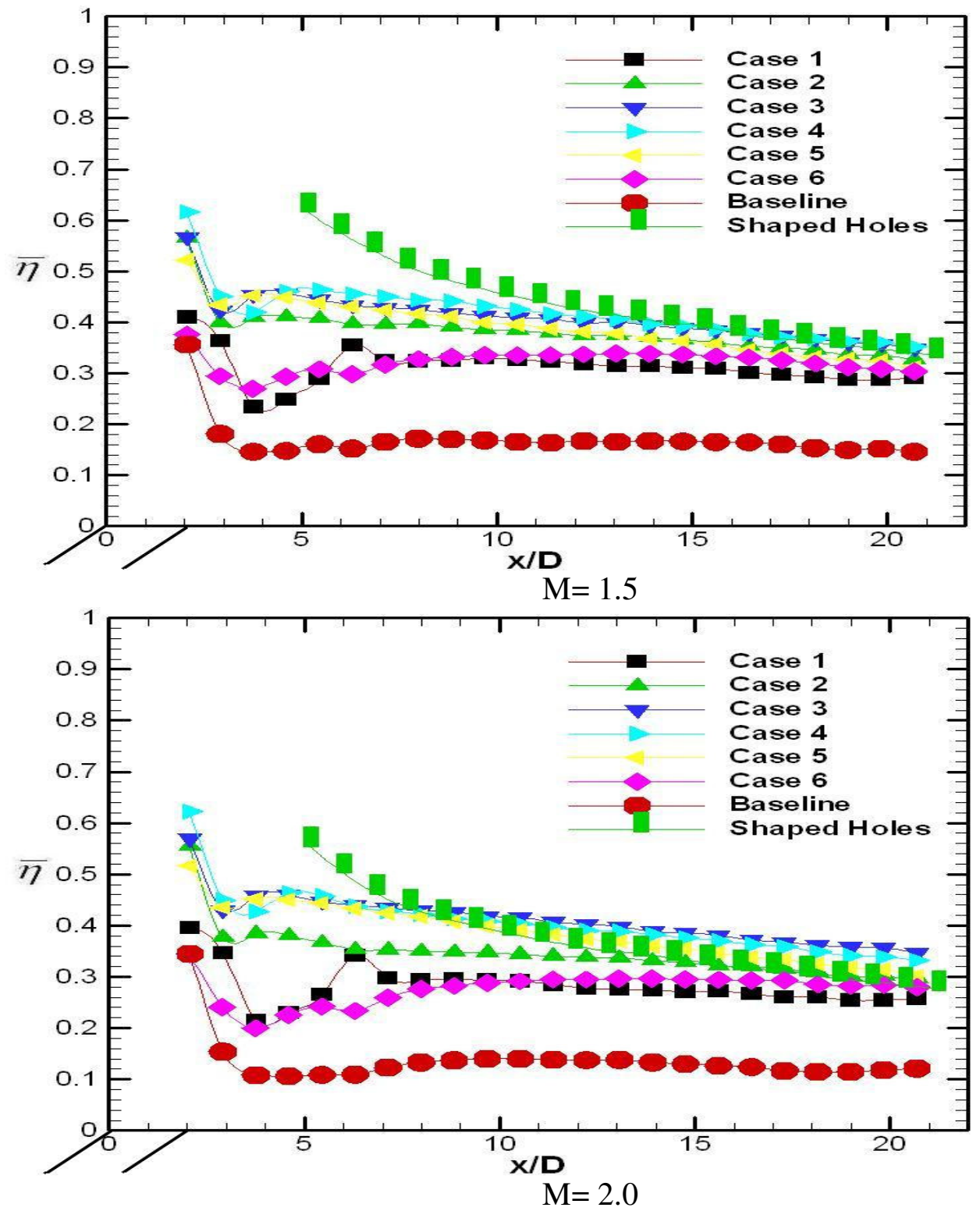

Figure 4.3c: Effect of Anti Vortex Hole Geometry on Spanwise Averaged Film Cooling Effectiveness Distributions at Blowing Ratio 1.5 and 2.0

For blowing ratio of $\mathrm{M}=1.5$, case 4 has the highest film cooling effectiveness which is only slightly better than case 3 and case 5 . Case 1 and case 6 show similar levels with slightly higher effectiveness than the baseline case. For the highest blowing ratio of $M=2$, case 3 
produces slightly higher effectiveness than case 4 . The effectiveness of case 2 and case 5 are also relatively higher and are comparable to that of case 4 and case 3 .

The presence of anti vortex holes in the nearby region of the main film cooling holes clearly shows an increment in the film cooling effectiveness. This can be attributed to lowering the momentum of the primary coolant jet due to decrease in mass flow rate. A second factor would be better film coverage in space between the two primary holes. As blowing ratio increase, the anti vortex design produces film effectiveness at similar levels as the shaped hole indicating that the shaped hole can be replaced by anti vortex design without any loss to coolant performance.

\subsection{Spanwise Averaged Heat Transfer Coefficient Ratio}

Figures $4.4 \mathrm{a}, 4.4 \mathrm{~b}, 4.4 \mathrm{c}$ and $4.4 \mathrm{~d}$ presents the effect of anti vortex hole geometry and orientations on spanwise averaged heat transfer coefficient ratio $\left(h / h_{0}\right)$ for each blowing ratio. The local heat transfer coefficient with film cooling $(h)$ is normalized by the heat transfer coefficient without film holes on a flat surface $\left(h_{0}\right)$.

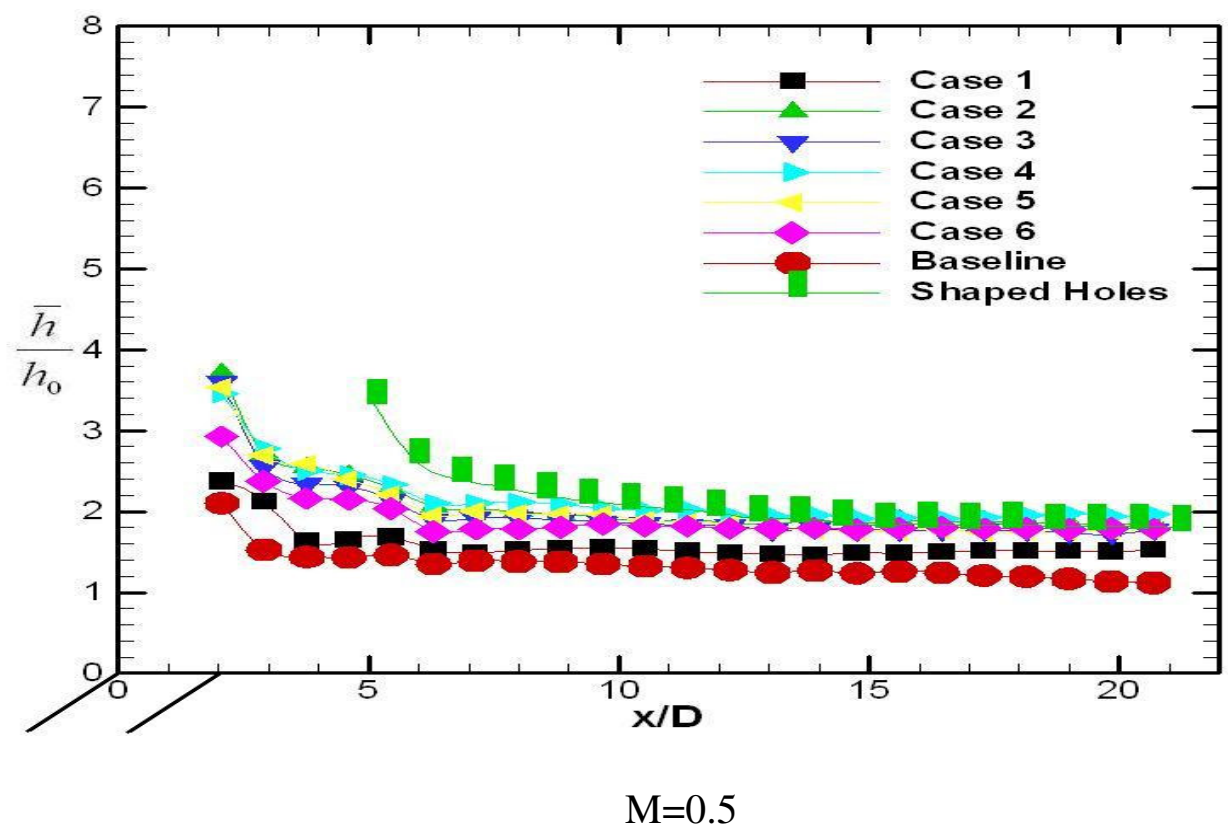

Figure 4.4a: Effect of Anti Vortex Hole Geometry on Spanwise Averaged Heat Transfer Coefficient Ratio Distributions at Blowing Ratio 0.5 
The downstream exit point of the primary hole is at the location $\mathrm{x} / \mathrm{D}=2$. At a low blowing ratio of $\mathrm{M}=0.5$, the heat transfer coefficients for cases $2,3,4,5$ and shaped holes look similar beyond $\mathrm{X} / \mathrm{D}=5$. These cases also had better film cooling effectiveness. It indicates that the mixing of the mainstream and jet provides a better coverage film but increases local turbulence production enhancing the heat transfer coefficient. Owing to high film effectiveness and low relative heat transfer coefficient, case 5 is clearly the best choice, behind shaped holes at this low blowing ratio of $\mathrm{M}=0.5$.

At $M=1.0$, case 5 appears to have the lowest heat transfer coefficient amongst cases 2, 3, 4 and 5, which have similar film cooling effectiveness at the same blowing ratio of $M=1$.

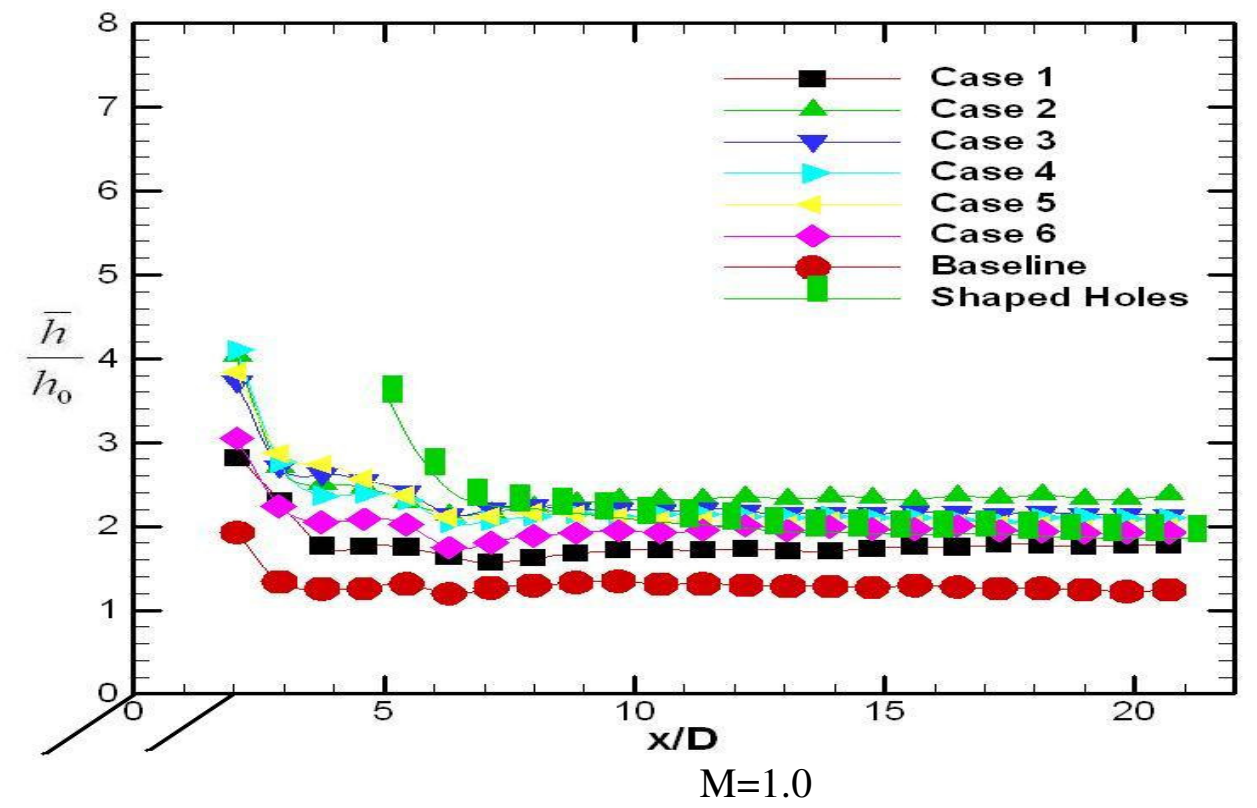

Figure 4.4b: Effect of Anti Vortex Hole Geometry on Spanwise Averaged Heat Transfer Coefficient Ratio Distributions at Blowing Ratio 1.0

For $M=1.5$, for cases considered above, case 5 seems to have the lowest heat transfer coefficient. For $M=2$, case 3 has the highest heat transfer coefficient. For Case 2 the coefficient is less due to the lift off of the jet. Heat transfer co efficient of case 4 appears to be lesser than case 5. In the immediate downstream vicinity of the shaped holes, there is a slight higher heat 
transfer coefficient but farther downstream, the shaped hole shows lower values than cases 2-5.

It is clear that the anti-vortex pair enhance heat transfer coefficient over the baseline case.

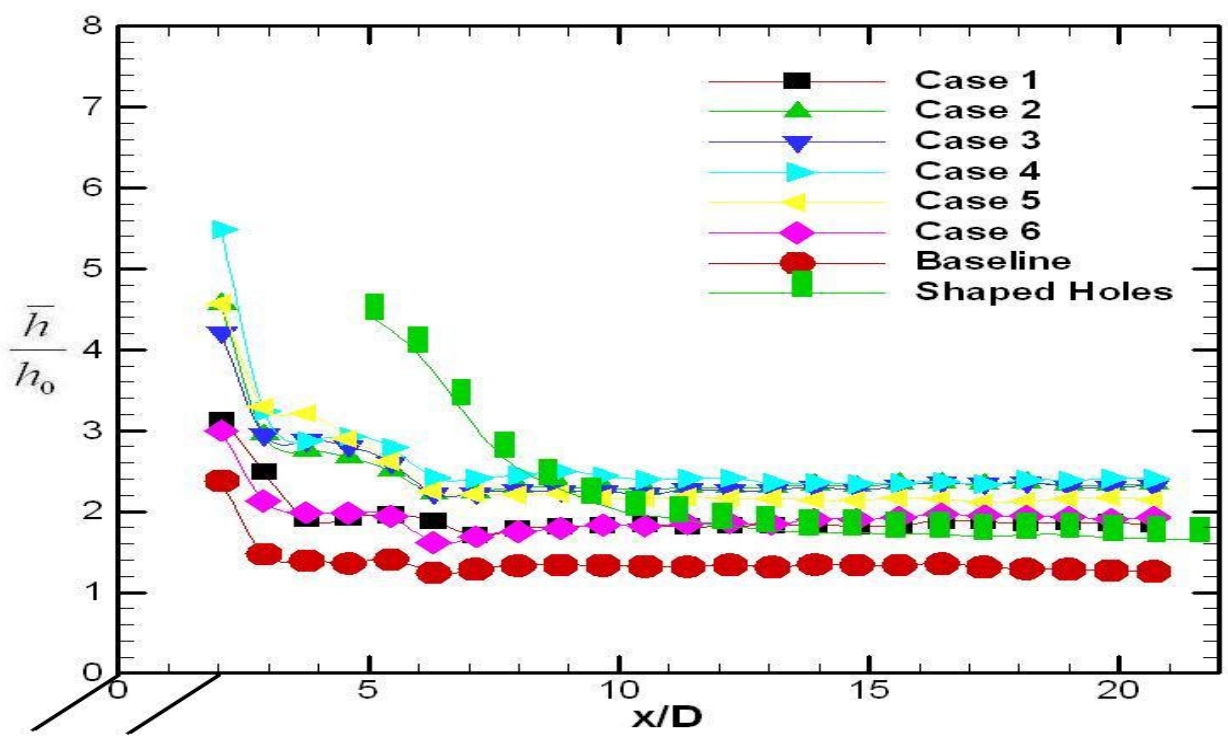

$$
\mathrm{M}=1.5
$$

Figure 4.4c: Effect of Anti Vortex Hole Geometry on Spanwise Averaged Heat Transfer Coefficient Ratio Distributions at Blowing Ratio 1.5

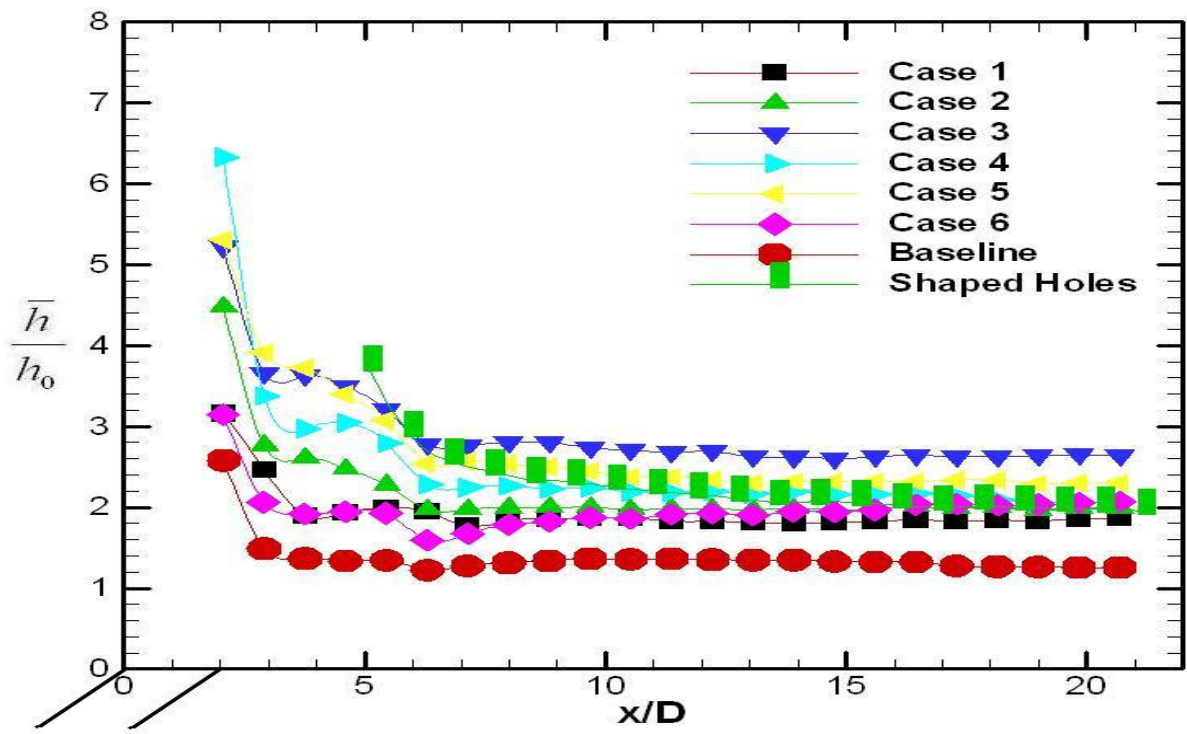

$\mathrm{M}=2.0$

Figure 4.4d: Effect of Anti Vortex Hole Geometry on Spanwise Averaged Heat Transfer Coefficient Ratio Distributions at Blowing Ratio 2.0 


\subsection{Overall Area Averaged Film Cooling Effectiveness}

Figure 4.5 presents the effect of blowing ratio on the overall area-averaged film effectiveness for all cases. As seen clearly from the plot, film effectiveness is mostly at the same level for increase in blowing ratio from $M=0.5$ to 1.0 for nearly all cases except cases 3,4 and 6 which seem to increase a little.

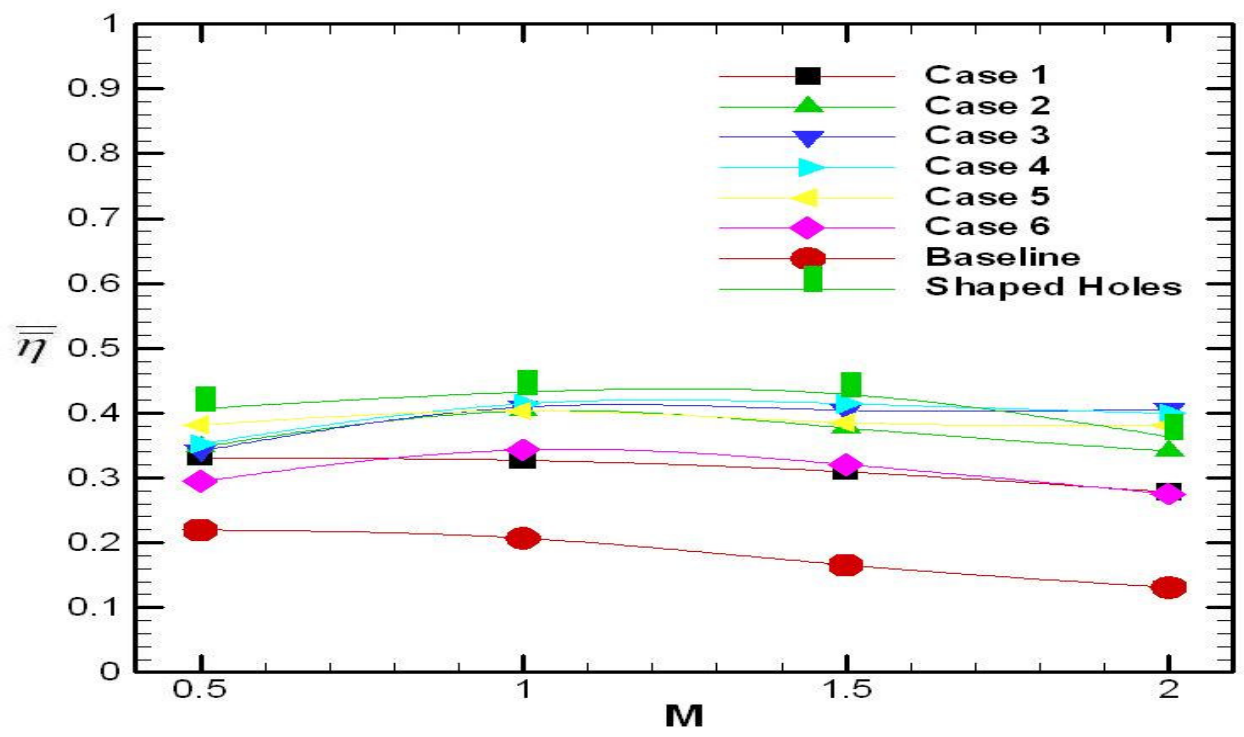

Figure 4.5: Effect of Blowing Ratio on Overall Area-Averaged Film Effectiveness

From $M=0.5$ to higher blowing ratios, cases 2 and 6 , baseline and shaped holes seems to have lower area averaged film cooling effectiveness. For other cases, there seems to be no effect of increment in blowing ratio.

\subsection{Overall Area Averaged Heat Transfer Coefficient Ratio}

Figure 4.6 presents the effect of blowing ratio on the overall area-averaged heat transfer coefficient for all cases. Heat transfer coefficient ratios for case 3 and 5 seem to be increasing with increasing blowing ratio. For shaped holes, the ratio seems to be a constant till $\mathrm{M}=1.5$, after which it starts to increase. For cases 2 and 4, there seems to be an increase in the ratio when the blowing ratio increases from $\mathrm{M}=0.5$ to $\mathrm{M}=1.5$, after which it decreases. 


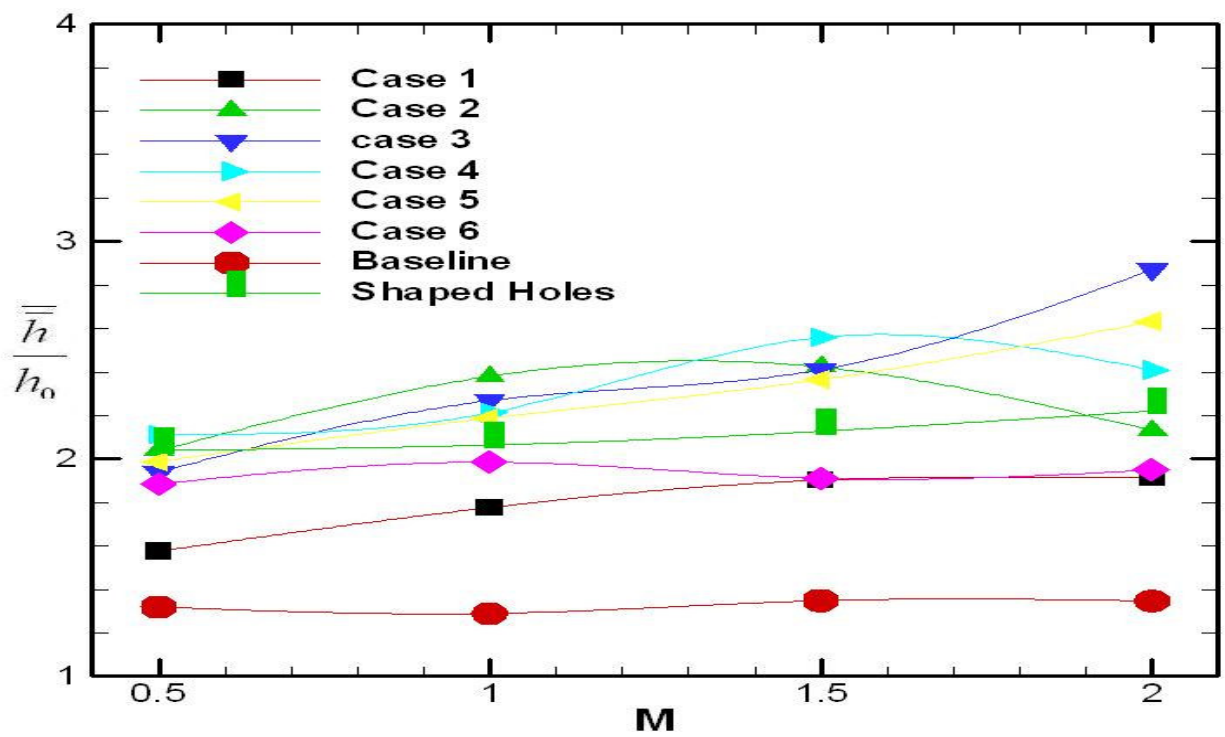

Figure 4.6: Effect of Blowing Ratio on Overall Area-Averaged Heat Transfer Coeff. Ratio

\subsection{Overall Area Averaged Heat Flux Ratio}

Figure 4.7 presents the effect of blowing ratio on overall area-averaged heat flux ratio $\left(q^{\prime \prime} / q_{o}{ }^{\prime \prime}\right)$ for all three cases. This ratio indicates the reduction in heat flux obtained by introduction of film cooling over the surface. If the value is below 1.0, the effect is positive. If the value is greater than 1.0, then the presence of film cooling is detrimental.

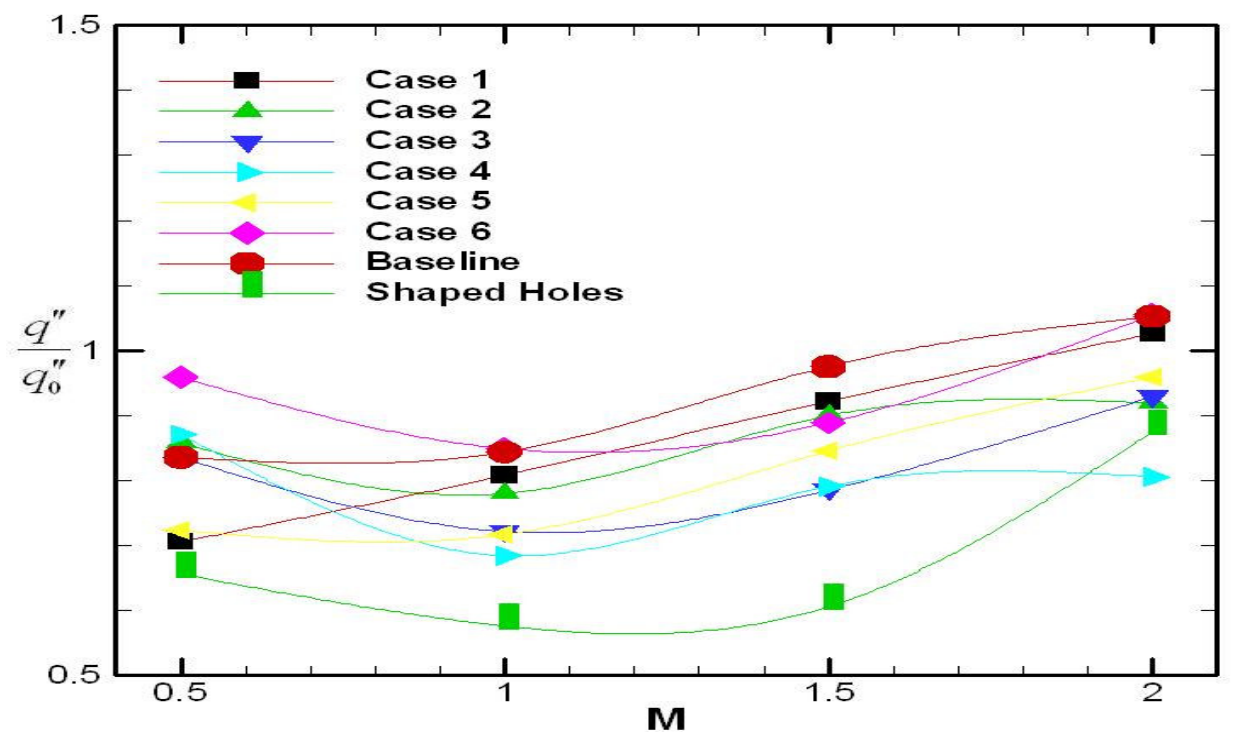

Figure 4.7: Effect of Blowing Ratio on Overall Heat Flux Ratio 
It is clear from the plot that except for case 3 and case 1 , all other anti vortex cases have a positive result. Between $\mathrm{M}=0.5$ and $\mathrm{M}=1$, case 5 provides better protection. Case 4 and case 3 work better at blowing ratios between $\mathrm{M}=1$ and $\mathrm{M}=2$ Overall, it appears that cases 3,4 , and 5 all provide much better performance than the baseline case.

\subsection{Discussions}

CFD studies on film cooling from anti vortex hole case 6 has been done by Heidmann et al. [28]. It is seen that the flow interaction between the anti vortex holes protruding from adjacent main holes interact to form a vortex whose sense is opposite to the vortex formed due to mainstream - coolant jet interaction. This new vortex formed mitigates the effect of the vortex formed due to mainstream-coolant jet interaction in the downstream region. Figure 4.8 show the ratio of mainstream temperature to local temperature $\left(\mathrm{T} / \mathrm{T}_{\mathrm{in}}\right)$ and secondary flow vectors on a plane normal to the surface at $\mathrm{x} / \mathrm{d}=5$ for baseline case at blowing ratio 1.0 . This streamwise location is representative of the region where film cooling jet liftoff is expected to occur for the baseline case at moderate to high momentum ratio.

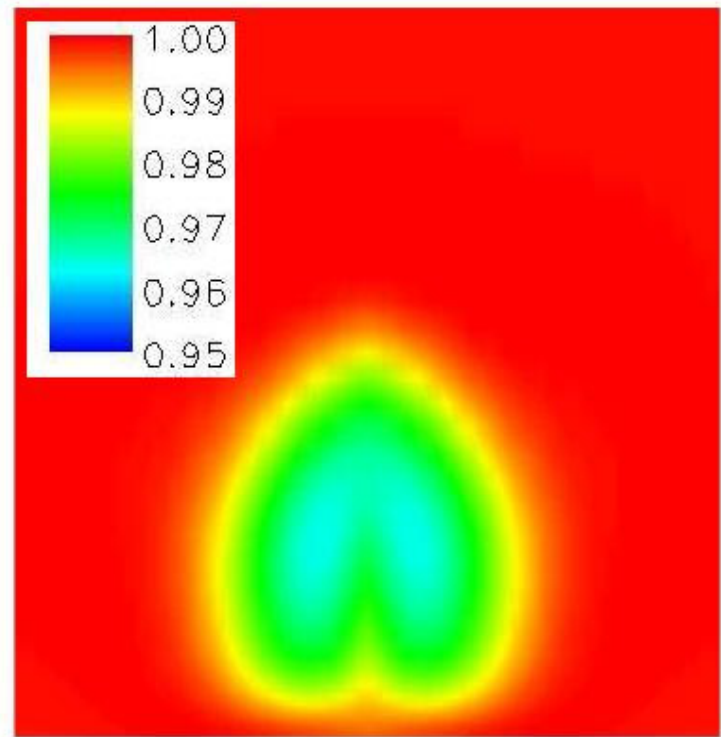

(a)

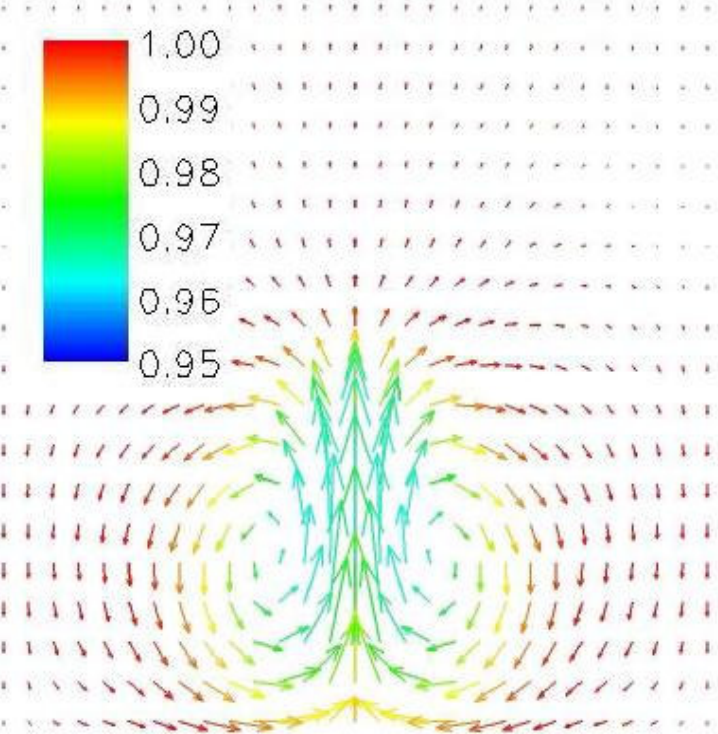

(b)

Figure 4.8 (a) Stagnation temperature $\left(\mathrm{T} / \mathrm{T}_{\text {in }}\right)$ and (b) Secondary Flow Vectors Colored by Temperature at $\mathrm{x} / \mathrm{d}=5$ for Baseline at Blowing Ratio 1.0 
Figure 4.8 clearly shows the presence of strong vortices due to coolant jet and mainstream interaction which causes "jet lift off". The temperature of the jet is considerably lower than that of the mainstream.

Figure 4.9 shows a similar picture for the Anti Vortex Film Cooling Hole case-6. The formation of anti vortices is clearly seen. Although the strength of these anti vortices are not as strong as the primary vortices, but it counters the primary vortices and the coolant jet remains attached to the blade surface. The temperature of the base in this case is clearly lowered.

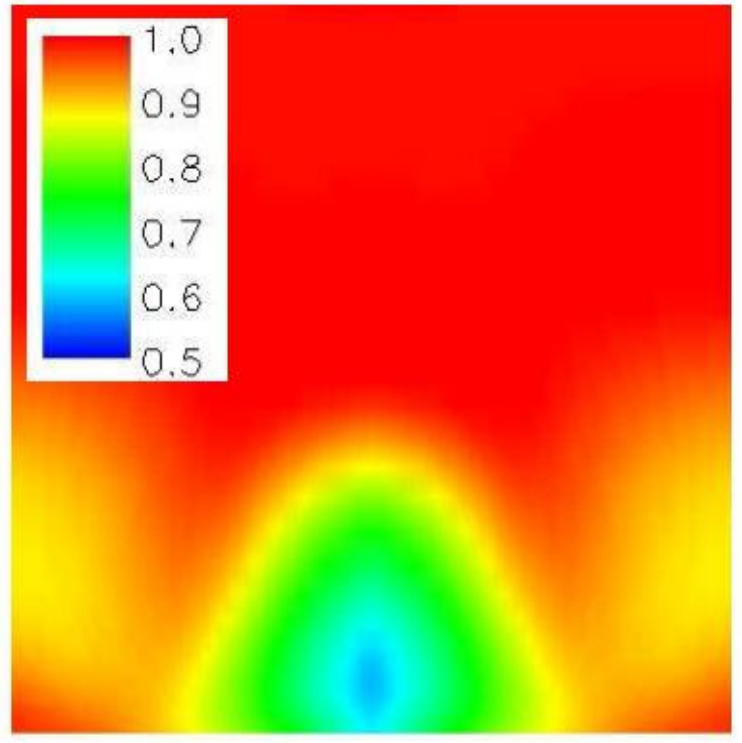

(a)

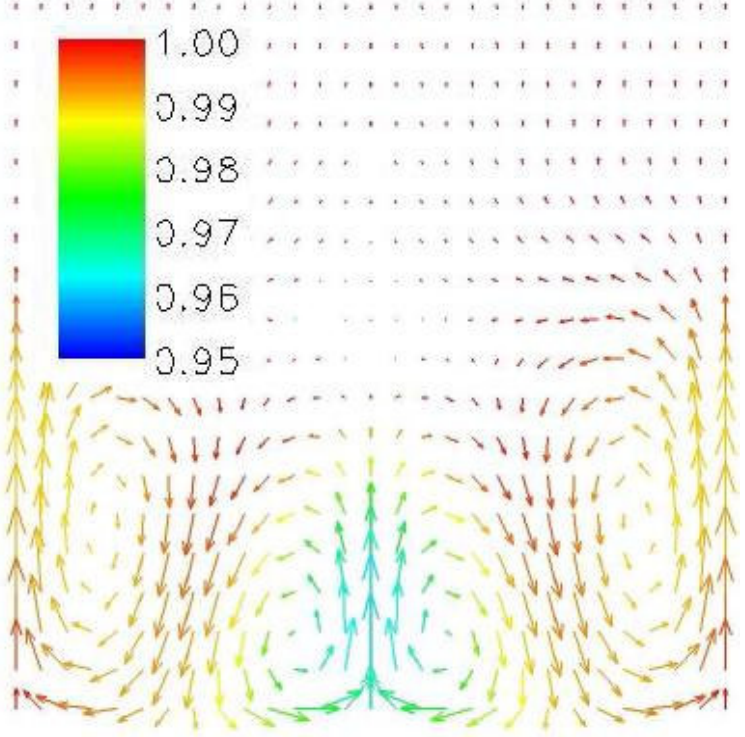

(b)

Figure 4.9 (a) Stagnation temperature $\left(\mathrm{T} / \mathrm{T}_{\text {in }}\right)$ and (b) Secondary Flow Vectors Colored by Temperature at $\mathrm{x} / \mathrm{d}=5$ for Case 6 at Blowing Ratio 1.0

Owing to the better results obtained for cases 4 and 5 as compared to case 6 , it can be said that the anti vortices produced in the former cases are stronger than the one formed in the latter case. The stronger anti vortices produced greatly mitigates the effect of the vortices formed due to the mainstream and coolant jet interaction. CFD study for these cases and flow visualization techniques can further throw some light into this matter. 


\section{CHAPTER 5: CONCLUSIONS}

A low speed wind tunnel was used for a detailed film cooling study on the effects of geometry and orientations of anti-vortex holes branching out from the primary holes on a flat plate. For all the cases, both heat transfer coefficients and film cooling effectiveness were measured using a transient infrared thermography technique. It appears that the presence of anti vortex holes mitigates the effect of the kidney vortices and also reduces the momentum of the main jet hence bettering the film coverage in both downstream and lateral direction. Cases 3, 4, 5 are clearly the better choices for their low overall heat flux ratio. Case 5 however may pose a problem in structural integrity for there is a very narrow piece of material that separates the main hole from the anti vortex holes. Cases 3 and 4 clearly are equivalent in performance to the industry standard diffuser shaped holes and may be a good alternative in terms of manufacturability.

To better understand the physics of the promising results from cases 3, 4 and 5, CFD study on these cases would be very helpful. The next step on the experimental avenue would be to study the effects of anti vortex holes on curved turbine surface in a linear blade cascade. 


\section{REFERENCES}

1. Gas Turbine, http://www.allrefer.com/pictures/s1/g0057200-gas-turbine ,2007.

2. Saunter, M., Clouser, S., and Han, J. C., 1992. "Determination of Surface Heat Transfer and Film Cooling Effectiveness in Unsteady Wake Flow Conditions." AGARD Conference Proceedings 527, pp. 6-1 to 6-12.

3. Han, J.C., Park, J.S., and Lie, C.K., 1984. "Heat Transfer and Pressure Drop in Blade Cooling Channels with Turbulence Promoters." Texas A\&M University (prepared for NASA CR-3837)

4. Goldstein, R.J., 1971. "Film Cooling" In Advancement in Heat Transfer. Academic Press, New York, Vol.7, pp321-379

5. Hay, N. and Lampard, D., 1996, "Discharge Coefficient of Turbine Cooling Holes: A Review." ASME paper 96-GT-492

6. Han, J. C., Sandip Dutta, and Srinath V. Ekkad. Gas Turbine Heat Transfer and Cooling Technology. Taylor \& Francis Group, 2001

7. Andreopoulous ,J. and Rodi, W., 1984 Experimental Investigation of Jets in Crossflow Journal of Fluid Mechanics, Vol 138, pp 93-127

8. B.A. haven and M. Kurosaka., Improved Jet Coverage Through Vortex Cancellation ,AIAA Journal, Vol. 34, No. 11

9. Lemmon, C. A. , Kohli, A. , Thole, K. A. " Formation of Counter Rotating Vortices in Film Cooling Flows

10. Haven ,B.A., Yamagata, D. K., Kurosaka ,M., Yamawaki, S., Maya,T., 1997, “Anti kidney Pair of Vortices in Shaped Holes and their Influence on Film Cooling Effectiveness" ASME Paper 97-GT-45

11. Ligrani, P. M., Wigle, J. M., Ciriello, S., and Jackson, S.W., “ Film-cooling From Holes with Compound Angle Orientations: Part 1- Results Downstream of Two Staggered Rows of Holes with 3d Spanwise Spacing," ASME Journal of Heat Transfer, Vol. 116, No. 2, 1994, pp. 341-352.

12. Ligrani, P. M., Wigle, J. M., and Jackson, S.W., " Film-cooling From Holes with Compound Angle Orientations: Part 2- Results Downstream of a Single Row of Holes with 6d Spanwise Spacing," ASME Journal of Heat Transfer, Vol. 116, No. 2, 1994, pp. 353-362.

13. Sen, B., Schmidt, D.L., and Bogard, D. G., "Film Cooling with Compound Angle Holes: Heat Transfer," ASME Journal of Turbomachinery, Vol. 118, No. 4, 1996, pp. 801-807. 
14. Schmidt, D.L., Sen, B., and Bogard, D.G., "Film Cooling with Compound Angle holes: Adiabatic Effectiveness," ASME Journal of Turbomachinery, Vol. 118, No. 4, 1996, pp. 807-813.

15. Ekkad, S. V., Zapata, D., and Han, J.C., "Heat Transfer Coefficients Over a Flat Surface with Air and $\mathrm{CO}_{2}$ injection Through Compound Angle holes Using a Transient Liquid Crystal Image Method," ASME Journal of Turbomachinery, Vol. 119, No. 3, 1997, pp. 580-586.

16. Ekkad, S. V., Zapata, D., and Han, J.C., "Film Effectiveness Over a Flat Surface with Air and $\mathrm{CO}_{2}$ injection Through Compound Angle holes Using a Transient Liquid Crystal Image Method," ASME Journal of Turbomachinery, Vol. 119, No. 3, 1997, pp. 587-593.

17. Makki, Y., and Jakubowski, G., 1986, "An Experimental Study of Film Cooling From Diffused Trapezoidal Shaped holes,” AIAA Paper 86-1326.

18. Gritsch, M., Schulz, A., and Wittig, S., "Heat Transfer Coefficient Measurements of Film Cooling Holes with Expanded Slots," American Society of Mechanical Engineers, ASME Paper 98-GT-28, June 1998.

19. Gritsch, M., Schulz, A., and Wittig, S., "Adiabatic Wall Effectiveness Measurements of Film Cooling Holes with Expanded Exits," ASME Journal of Turbomachinery, Vol. 120, No. 3, 1998, pp. 549-556.

20. Dittmar, J., Schulz, A., and Wittig, S., 2002, "Assessment of various film cooling configurations including shaped and compound angle holes based on large scale experiments," ASME GT-2002-30176.

21. Sargison, J. E., Guo, S. M., Oldfield, M. L.G., Lock, G. D., and Rawlinson, A. J., 2002, "Flow Visualization of a Converging Slot-Hole Film Cooling Geometry," ASME Paper GT 2002-30177.

22. Lu, Y., Faucheaux, D., and Ekkad, S.V., 2005, "Film Cooling Measurements for Novel Hole Configurations," ASME Summer Heat Transfer Conference, July 2005, Paper No. HT2005-72396

23. Incropera, F. P. and DeWitt, D. P. Introduction to Heat Transfer, New York: John Wiley \& Sons, 2002

24. Ekkad, S. V., Han, J.C., and Du, H., 1998, "Detailed Film Cooling Measurement on a Cylindrical Leading Edge Model: Effect of Free-Stream Turbulence and Coolant Density." ASME Journal of Turbomachinary, Vol. 120, pp. 799-807.

25. Vedula, R. P., and Metzger, D. E., 1991, "A Method for the Simultaneous Determination of Local Effectiveness and Heat Transfer Distributions in a Three Temperature Convective Situations," ASME Paper 91-GT-345. 
26. Ekkad, S. V., Ou, S. and Rivir, R. V., 2004, “A Transient Infrared Thermography Method for Simultaneous Film Cooling Effectiveness and Heat Transfer Coefficient Measurements from a Single test," GT2004-54236, Proceedings of ASME Turbo Expo 2004, Vienna, Austria.

27. Kline, S.J. and McClintock, F.A., 1953, "Describing Uncertainties in Single Sample Experiments," Mechanical Engineering, Vol. 75, pp. 3-8.

28. Heidmann, J., and Ekkad, S. V., 2007, “A Novel Anti-Vortex Turbine Film Cooling Hole Concept," Proceeding of GT 2007, Turbo Expo 2007: Power for Land, Sea and Air, May 14-17 Montreal, Canada.

29. Alok Dhungel, Yiping Lu, Wynn Phillips, Srinath V. Ekkad, James Heidmann, 2007, "Film Cooling from a row of Holes Supplemented with Anti Vortex Holes," Proceeding of GT 2007, Turbo Expo 2007: Power for Land, Sea and Air, May 14- 17 Montreal, Canada. 


\section{VITA}

Alok Dhungel was born in January 1979 to Mr. Mahendra P. Dhungel and Mrs. Bimala Dhungel in Kathmandu, Nepal. He attended The Elite's Co-ed. School, Kathmandu and completed Intermediate in Science in May 1979 from St. Xavier's Campus in Kathmandu, Nepal. Alok then studied under student exchange scholarship program at Regional Engineering College, Rourkela, India where he earned his Bachelor of Engineering in mechanical engineering in May of 2002. He then continued his education at Louisiana State University, Baton Rouge pursuing a Master of Science in Mechanical Engineering under the guidance of Dr. Srinath V. Ekkad. Having fulfilled the requirements set forth by the Graduate School and the Department of Mechanical Engineering, Alok will graduate in August of 2007. 